\title{
COP1 CONTRIBUTES TO UVB-INDUCED SIGNALING IN HUMAN KERATINOCYTES
}

Ph.D. Dissertation

\section{Ágnes Kinyó}

\author{
Supervisor: \\ Prof. Dr. Lajos Kemény \\ Department of Dermatology and Allergology \\ University of Szeged, Szeged, Hungary
}

2011 


\section{TABLE OF CONTENTS}

\section{LIST OF PUBLICATIONS}

1. INTRODUCTION 6

1.1. COP1, the Constitutive Photomorphogenic Protein $1 \quad 6$

1.1.1. Definition 6

1.1.2. COP1 in plants 6

1.1.3. COP1 in non-plant organisms

1.1.4. Structural and functional analogy between AtCOP1 and 7 mammalian COP1

1.2. Function of mammalian COP1 9

1.3. p53 regulation in keratinocytes and in the epidermis 10

1.4. E3 ubiquitin ligases and p53 regulation 11

1.5. Kinetics of p53 and COP1 expression during keratinocyte 12 differentiation

1.6. Effects of genotoxic stress on E3 ubiquitin ligases 13

1.7. COP1 in human tumors $\quad 14$

2. AIMS 15

3. MATERIALS AND METHODS 16

3.1. Normal human keratinocytes and HaCaT keratinocyte cultures $\quad 16$

3.2. Immunocytochemistry, immunohistochemistry and immunofluorescence 16 staining

3.3. Constructs 18

3.4. Nucleofection 18

3.5. UVB irradiation (FS20 lamp, excimer laser) 19

3.6. Reverse transcription and real-time RT-PCR 20 
4. RESULTS 22

4.1. COP1 expression and subcellular localization in cultured 22 normal human keratinocytes and HaCaT cells

4.2. COP1 and p53 expression in UVB-irradiated keratinocytes 24

4.3. Up-regulated p53 protein expression is further increased by 29 UVB irradiation in COP1 gene-silenced cells

4.4. COP1 expression in normal and UVB-irradiated human skin 30

4.5. COP1 protein and keratinocyte differentiation 32

$\begin{array}{ll}\text { 5. DISCUSSION } & 34\end{array}$

6. SUMMARY 40

7. ACKNOWLEDGMENTS 42

8. REFERENCES 43 


\section{LIST OF PUBLICATIONS}

I. Ágnes Kinyó, Zsuzsanna Kiss-László, Szabolcs Hambalkó, Attila Bebes, Mária Kiss, Márta Széll, Zsuzsanna Bata-Csörgő, Ferenc Nagy and Lajos Kemény: COP1 Contributes to UVB-Induced Signaling in Human Keratinocytes. Journal of Investigative Dermatology 130, 541-545; (2010)

IF: $\mathbf{5 , 5 4 3}$

II. Kemény Lajos dr., Kinyó Ágnes dr., Hambalkó Szabolcs, Bebes Attila, Kiss Mária dr., Polyánka Hilda, Kiss-László Zsuzsanna dr., Bata-Csörgő Zsuzsanna dr., Nagy Ferenc dr., Széll Márta dr.: A COP1 az UVB-indukált jelátviteli út tagja humán keratinocitákban. Börgyógyászati és Venereológiai Szemle 85 (2), 49-54; (2009)

III. Kemény Lajos dr., Kinyó Ágnes dr., Baltás Eszter dr., Csoma Zsanett dr., Dósa Piroska dr., Gyulai Rolland dr., Bata Zsuszanna dr., Dobozy Attila dr. A 308 nm-es excimer lézer a psoriasis kezelésében. Börgyógyászati és Venereológiai Szemle 82 (2), 67-71. (2006)

\section{Publications indirectly related to the subject of the dissertation}

1. Kinyó Ágnes dr., Gyulai Rolland dr., Varga Erika dr., Korom Irma dr., Bata-Csörgő Zsuzsanna dr., Kemény Lajos dr., Allopurinol-okozta hiperszenzitivitási szindróma. Börgyógyászati és Venereológiai Szemle 84 (3) 86-89. (2008)

2. Kinyó Ágnes, Belső Nóra, Nagy Nikoletta, Pálvölgyi Attila, Nagy István, Korom Irma, Varga Erika, Kemény Lajos, Bata-Csörgő Zsuzsanna. Strontium Ranelate-induced DRESS Syndrome with Persistent Autoimmune Hepatitis. Acta Derm Venereol. 2011 Jan 17. doi: 10.2340/00015555-1014. [Epub ahead of print] No abstract available.

IF: 3,007 


\section{LIST OF ABBREVIATIONS}

AtCOP1: Arabidopsis thaliana COP1

ATM: ataxia telangiectasia mutated

BCIP/NBT: 5-bromo-4-chloro-3-indolyl phosphate/nitroblue tetrazolium

BSA: bovine serum albumin

bZIP: basic domain plus leucin zipper protein

CBB: Coomassie Brillant Blue

CIP1-8: COP1 interactive proteins

COP1: constitutive photomorphogenic protein 1

COP10: constitutive photomorphogenic protein 10

cry1-2: cryptochromes

cullin 4A: cullin gene 4A, ubiquitine ligase component

DAPI: 4',6-diamidino-2-phenylindole

DDB1: damage-specific DNA binding protein 1

DET1: de-etiolated homolog 1

EDTA: diaminoetán-tetraecetsav

FUS: gene family, suppression of chloroplast differentiation

GFP: green fluroescent protein

H1299: non-small cell lung carcinoma cell line

HeLa: cervical cancer cell line

HFR1: long hypocotyl in far-red

huCOP1: human constitutive photomorphogenic protein 1

HY5: elongated hypocotyl 5

HYH: HY5 homolog

IR: ionizing radiation

LAF1: long after far-red light 1

Mdm2: Murine double minute 2

MED: minimal erythema dose

MmCOP1: mammalian COP1

MTT: 3-(4,5-Dimethylthiazol-2-yl)-2,5-diphenyltetrazolium bromide dye

MTT: colorimetric assay to determine the cell viability, based on the detection of MTT dye uptake

MVP: major vault protein

NIH3T3: mouse embryonic fibroblast cell line

Pirh2: RING-H2 domain-containing protein

phyA-B: phytochromes

RWD2: ring finger and WD repeat domain 2 (COP1)

RING: conserved pattern of cysteine and histidine residues that bind two zinc atoms

Roc1: Rotamase CYP 1

SDS-PAGE: sodium dodecylsulfate-polyacrylamide gel electroforesis

SPA: suppressor of phya-105 1

STH: STO homolog, B-box zinc finger protein that interacts with COP1

STO: salt tolerance protein

TBST: (Tris-buffered saline containing 0.1\% Triton-X

U2OS: osteosarcoma cell line

WD40: Trp-Asp repeats domain 


\section{INTRODUCTION}

\subsection{COP1, the Constitutive Photomorphogenic Protein 1}

\subsubsection{Definition}

UVB light, one of the most important physical carcinogens in the environment, has been shown to trigger a broad range of changes in gene expression in plants and in non-plant multicellular organisms (1-5). Only plants and some bacteria are able to absorb sunlight directly and plants have developed sophisticated mechanisms to sense light conditions and adjust their developmental programs accordingly (6). Many components of the light signaling cascades have been revealed over the years, mostly by genetic approaches. Among them, COP1 (constitutive photomorphogenic protein 1) was one of the first cloned and is one of the most extensively studied. COP1 is a RING-finger protein; it was first described in Arabidopsis thaliana (7).

\subsubsection{COP1 in plants}

It has been established that Arabidopsis thaliana COP1 (AtCOP1) functions as an essential negative regulator of light-mediated plant development, as evidenced by cop1 mutant seedlings undergoing photomorphogenic development even in the absence of light, and plants with cop1 null alleles never survive to the adult stage (7). AtCOP1, an E3 ubiquitin ligase, is essential for the proteasome-dependent degradation of a number of bZIPtype transcription factors, such as HY5, HYH, LAF1 and HFR1 (8). Genome-wide microarray analysis has demonstrated that AtCOP1 regulates most, if not all, of the lightresponsive genes under various light conditions (1). AtCOP1 functions as a crucial developmental switch through targeting key transcription factors for degradation, thereby controlling light-responsive gene expression and photomorphogenic development $(9,10)$.

In photosynthetizing cells, the subcellular distribution of AtCOP1 is adjusted according to the light conditions. In darkness, AtCOP1 is mainly localized to the nucleus, 
where it presumably targets photomorphogenesis-promoting transcription factors for ubiquitination and degradation, thereby repressing the expression of photomorphogenesis genes. When cells are exposed to light, there are drastic reductions in AtCOP1 levels in the nucleus, allowing nuclear-localized transcription factors to re-accumulate. These transcription factors activate the transcription of downstream genes required for plants to undergo photomorphogenesis $(11,12)$.

\subsubsection{COP1 in non-plant organisms}

Although, COP1 also exists in non-plant multicellular organisms, its function is less understood among vertebrates, COP1 is well conserved among fish, amphibians, birds and mammals, it is apparent that, unlike plants, animals do not undergo photomorphogenesis. Several initial studies have implied that animal COP1 may have adopted roles in tumorigenesis and stress response, although its biochemical activities and some of the signaling elements it interacts with appear to be conserved between plants and animals (13).

\subsubsection{Structural and functional analogy between AtCOP1 and mammalian COP1}

Mammalian COP1 (MmCOP1), as human COP1 (huCOP1), is located at chromosome 1 and exhibits a high degree of sequence conservation and domain organization with AtCOP1 (Fig. 1), suggesting the possibility of functional conservation (13). Both MmCOP1 and AtCOP1 contain three conserved structural domains: a RING finger at the amino terminus, a coiled-coil domain in the middle, and a carboxyl-terminal WD40 repeat domain $(11,14-$ 16). Earlier studies suggested that COP1 acts primarily as a homodimer, and probably dimerizes through the coiled-coil domain $(8,10,13,17)$. The coiled-coil region and the seven WD40 motifs region comprise potential interaction domains for other protein partners. The discrete nuclear pattern of huCOP1 depends on the presence of these domains and is compatible with distribution to specific subnuclear compartments, as has been described for other RING proteins, such as promyelocytic leukemia protein (PML) (18). The RING-finger and the coiled-coil domains can function independently as light-responsive modules mediating the light-controlled nucleocytoplasmic partitioning of COP1. The seven C-terminal 
WD40 domains function as an autonomous repressor module since the overexpression of mutant COP1 with intact WD40 repeats is able to suppress photomorphogenic development (8) .

As compared with AtCOP1, MmCOP1 has an N-terminal extension that may be responsible for targeting COP1 to the nuclear envelope (NE) part of the nucleus. COP1 is predominantly localized in the nucleus, but a small amount may also be present in the cytosol. COP1 shuttles between the nucleus and the cytoplasm and forms subnuclear speckles in both plants and mammals. MmCOP1 and AtCOP1 utilize different nuclear import and nuclear export signals (NIS and NES) located in distinct regions for their nucleocytoplasmic shuttling and subnuclear localizations $(11,13)$.

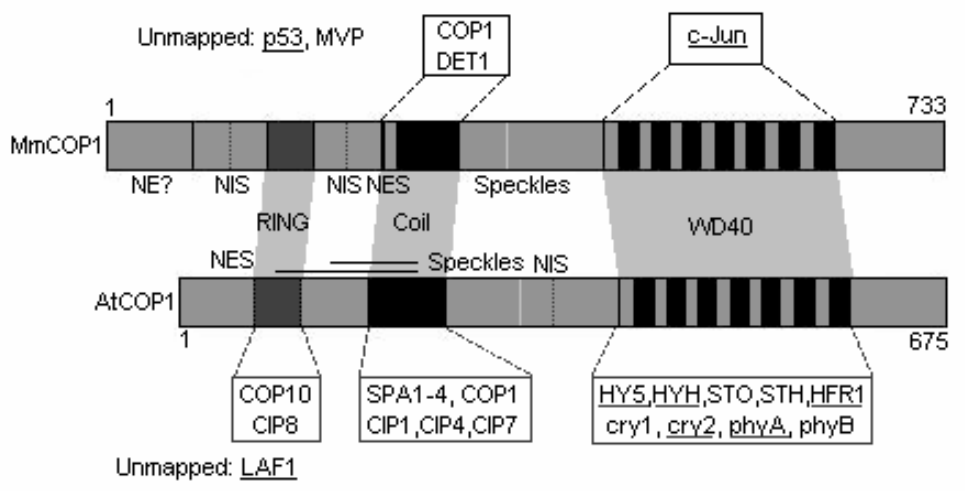

Figure 1. COP1 structural domains and interacting proteins. Both plant and mammalian COP1 proteins contain three structural domains: a RING finger, followed by a coiled-coil domain and seven WD40 repeats at the C-terminus. The AtCOP1 RING finger interacts with CIP8 and COP10. COP1 utilizes the coiled-coil domain for self-dimerization in both plants and mammals. In addition, the AtCOP1 coiled-coil domain interacts with SPA, CIP1, CIP4 and CIP7, while the coiled-coil domain of MmCOP1 has been implicated in binding to DET1. COP1 interacts through its WD40 repeats with HY5, HYH, STO, STH, HFR1, cry1, cry2, phyA and phyB in plants and with c-Jun in mammals. Other COP1-interacting factors whose interacting domains have not been mapped include LAF1 in Arabidopsis, and p53 and the major vault protein (MVP) in mammals (11). 


\subsection{Function of mammalian COP1}

MmCOP1, like AtCOP1, is involved in ubiquitination and is itself a substrate of its own ubiquitination activity $(11,13)$. COP1 ubiquitination substrates have been identified in mammals: c-Jun and p53 $(17,19)$. COP1-mediated p53 degradation is an important regulatory mechanism for the p53 function in the cell: depletion of COP1 leads to p53 accumulation and cell-cycle arrest, while the overexpression of COP1 inhibits p53-dependent apoptosis. Overexpression of huCOP1 in mammalian cells downregulates c-Jun-dependent transcription and expression of the AP-1 target genes, urokinases and matrix metalloproteinases $(13,20)$. It has been suggested that MmCOP1 functions as an adaptor protein recruiting c-Jun to an E3 complex, possibly containing DET1, DDB1, cullin4A and Roc1, through direct interaction with DET1 (Fig. 2) (17) . MmCOP1 binds to c-Jun through a conserved motif shared by the plant bZIP family COP1 substrates HY5 and HYH, and also represses c-Jun-mediated AP-1 transcription without affecting c-Jun protein levels (11) .
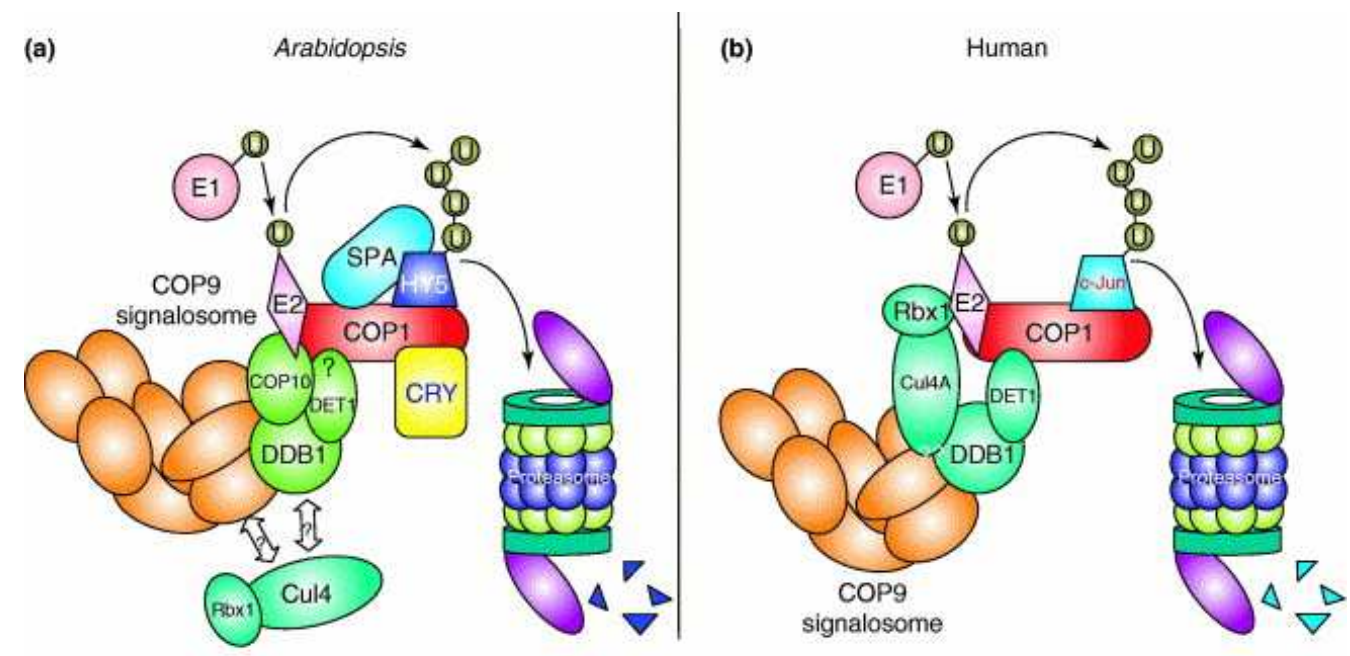

Figure 2. COP/DET/FUS proteins function collaboratively in mediating protein ubiquitination. The majority of the COP/DET/FUS proteins are conserved in both plants (a) and mammals (b). COP1 is able to target the bZIP transcription factors HY5 (in Arabidopsis) and c-Jun (in human) for ubiquitination and proteasome-mediated degradation (11) . 


\section{3. p53 regulation in keratinocytes and in the epidermis}

p53, a nuclear phosphoprotein first identified by Lane and Crawford in 1979, is encoded by a tumor suppressor gene on the short arm of chromosome 17 (21). It binds to DNA as a tetramer and activates the transcription of many genes involved in cell differentiation, proliferation, induction of DNA repair pathways and cell death $(5,22,23)$. The loss of p53 function by mechanisms such as mutations or binding to viral proteins increases the risk of development for certain types of cancers. p53 is mutated or deleted in more than $50 \%$ of human tumors and in most skin carcinomas $(22,24-28)$. As regards UVinduced skin tumors, p53 is considered to play an important role in their pathogenesis $(29,30)$.

In normal unstressed cells, p53 is a very unstable protein with a half-life ranging from 5 to $30 \mathrm{~min}$. Its short half-life is linked to polyubiquitination and proteasome-dependent degradation, while the protein is positively regulated through a succession of posttranslational modifications including phosphorylation and acetylation $(25,31,32)$. A hallmark of many cellular stress pathways, such as DNA damage, telomere shortening and oncogene activation, is the rapid stabilization of p53 via blocking its degradation (33). The p53 protein level is increased and stabilized in both murine and human keratinocytes when treated with UVB light (34). Its increased level is induced rapidly by UV irradiation as a result of posttranslational protein stabilization, although the translocation of cytoplasmic p53 to the nucleus may also contribute to protein stabilization (35) . p53 accumulates intracellularly up to readily detectable levels, arresting cells in the G1 phase, until cellular damage is fully repaired or the cell-death pathway is initiated (36) .

In normal human skin, p53 is generally not detected in the epidermis, which has been attributed to its relatively short half-life $(33,37-39)$. p53 is the key UV-responsive gene in skin, whose mutation is thought to initiate carcinogenesis, but its role in the control of keratinocyte proliferation and differentiation is less clear $(26,34)$. Epidermal keratinocytes are most susceptible to damage from UV light, because they are close to the skin surface. The epidermis is a stratified epithelium in which the basal layer contains stem cells and transient amplifying cells the latter that divide continuously to supply cells that enter the differentiating program and move up the epidermis $(40-42)$. 


\subsection{E3 ubiquitin ligases and $\mathbf{p 5 3}$ regulation}

p53 expression has been shown to be controlled by a plethora of upstream regulatory proteins (Fig. 3) $(28,43)$. p53 is tightly regulated: the main antagonists of human tumor suppressor p53 are Mdm2, Pirh2 and huCOP1 E3 ubiquitin ligases. These proteins directly promote p53 ubiquitination and its proteasome-dependent degradation. The proteasomes operate both in the nucleus and in the cytoplasm. Mdm2 interacts physically with and ubiquitinates p53, leading to its degradation in the cytosolic $26 \mathrm{~S}$ proteasome, but it has also been demonstrated that p53 degradation may occur in either the cytosolic or the nuclear proteasomes and does not require nuclear export $(44,45)$. In addition to Mdm2, Pirh2 and COP1 have been shown to impart specificity toward p53. The nuclear monoubiquitination of p53 by Mdm2 leads to the accumulation of p53. Following monoubiquitination, p53 may remain in the nucleus to be polyubiquitinated by Mdm2, Pirh2, COP1 or a complex of these proteins $(43,46,47)$.

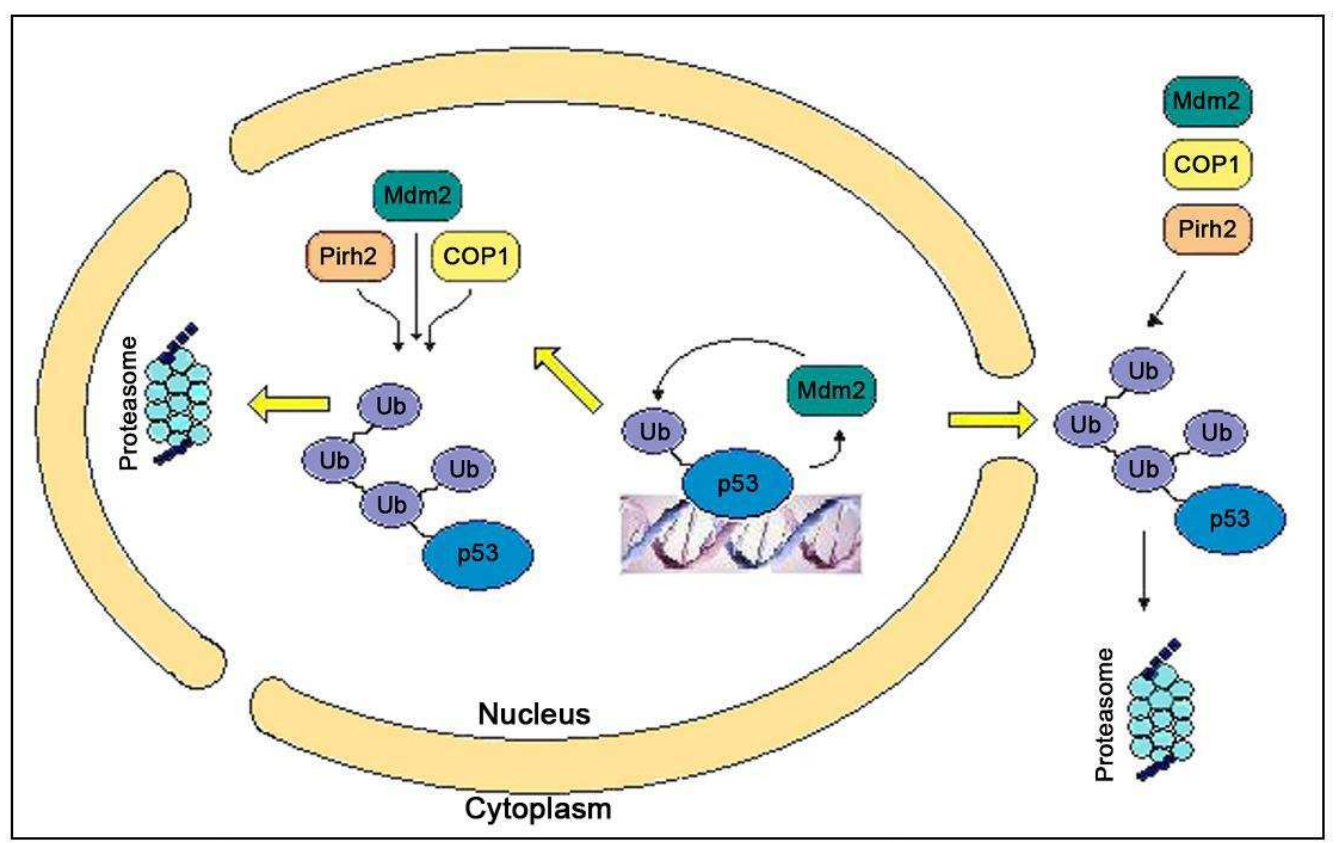

Figure 3. Potential model for the proteasomal degradation of p53 facilitated by Mdm2, Pirh2 and COP1 based on the investigations in H1299 cells $(43,45)$. 
Alternatively, p53 monoubiquitination by Mdm2 could promote the cytosolic accumulation of p53, where it is further polyubiquitinated by Mdm2, Pirh2, COP1 or a complex of these proteins, and degraded by cytosolic $26 \mathrm{~S}$ proteasomes. It has been demonstrated in U2OS osteosarcoma cells that COP1 promotes p53 turnover independently of Mdm2 or Pirh2 (19).

\subsection{Kinetics of p53 expression during keratinocyte differentiation}

Keratinocytes undergo a complex developmental program as they progress from the basal to the spinous, granular and finally the cornified layer of the epidermis (Fig. 4). p53 is expressed at low levels in UV-unexposed skin and is activated during the exit from the proliferative state, resulting in inhibition of cell division and stimulation of differentiation (48). Later, as the keratinocytes progress in the differentiation associated the cell death program, they become insensitive to p53-induced apoptosis $(39,48)$. UV light induces p53 in the proliferative compartment of the basal layer cells (49), resulting in cell cycle arrest and apoptosis, which protects from cancer induction $(22,34)$. When p53 is inhibited in the basal layer by a negative regulator protein (48), such as Mdm2, this leads to decreased differentiation and increased proliferation. Increased apoptosis is an indirect effect of the mechanisms that maintain homeostasis.

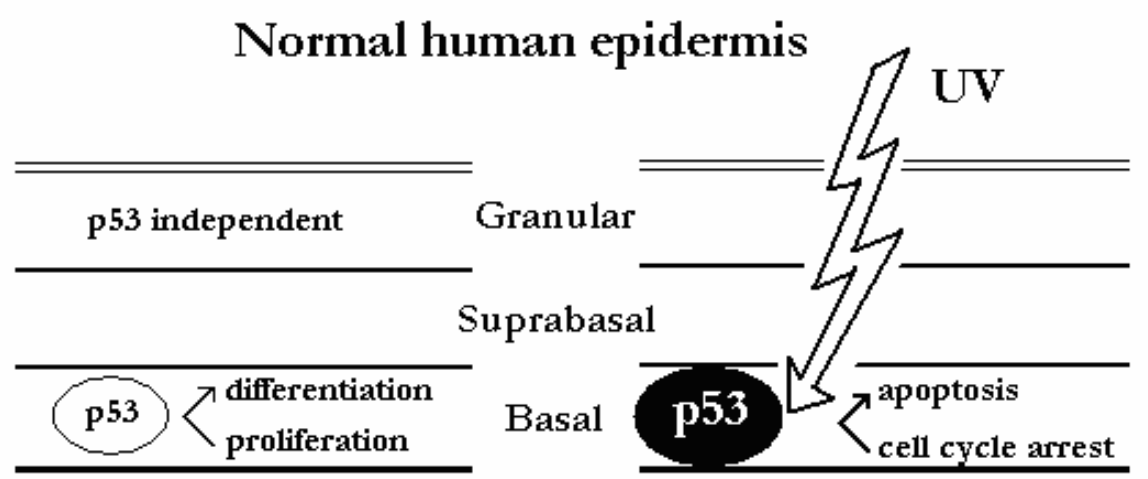

Figure 4. Potential model for the function of p53 in the different layers of the epidermis (48). 
Proliferation and differentiation are compartmentalized within the human epidermis. Keratinocytes proliferate in the basal layers perhaps as long as they are in contact with the extracellular matrix at and around the basement membrane (40). Proliferation is therefore controlled by integrins, the surface molecules that mediate cell adhesion. As the specific integrin functions are disrupted, keratinocytes migrate into the suprabasal layers, initiate terminal differentiation, enlarge, and ultimately produce the cornified envelope that sheds from the surface of the skin $(41,50,51)$. Within the basal layers, keratinocytes can be in two distinct states: the stem cell and the transit amplifying cell. Stem cells have a great capacity for self-renewal, but are thought to proliferate infrequently and be generally quiescent. As keratinocytes leave the stem cell compartment, they enter a continuous, but limited proliferative state, and after a few rounds of cell divisions, initiate terminal differentiation (40) .

Human keratinocytes undergo differentiation when placed in a serum-free medium with addition of the calcium ion $(50,52)$. It was earlier reported that p53 was downregulated as basal-like proliferating cells their proliferative potential, cell size increased, and an irreversible differentiation proceeds $(39,48)$. Differentiation may be monitored via detection of involucrin expression (53) .

\subsection{Effects of genotoxic stress on $\mathbf{E} 3$ ubiquitin ligases}

In wild-type p53 expressing cells, E3 ubiquitin ligases, such as Mdm2, Pirh2 and COP1, are induced following genotoxic stress, caused, for example, by ionizing radiation (IR) or UV irradiation $(43,54)$. Mdm2 expression increases in a p53-dependent manner following IR $(55,56)$, and its regulation after UVB irradiation in human keratinocytes is also well elucidated (57). Pirh2 expression is not enhanced following IR or UV treatment in wild-type p53-expressing cell lines, but it has not been investigated in human keratinocytes (31). COP1 protein expression increases following treatment with IR in wild-type p53 expressing cells (72), UVC results in biphasic mRNA changes and an elevated COP1 protein level in U2OS osteosarcoma cells and HeLa cells (58) . 


\subsection{COP1 in human tumors}

As COP1 is a critical negative regulator of p53 in normal and cancer cell lines (19), its role has been investigated in detail in human cancers. The overexpression of COP1 was detected predominantly, but not exclusively, in wild-type p53-containing cancers, such as ovarian tumors, breast adenocarcinomas (59) and hepatocellular carcinomas (60), indicating that one of the major roles of COP1 is to repress p53-dependent tumor suppression. Finally, COP1 may function as an oncogene and promote tumorigenesis, especially in tumors in which p53 is not mutated. Investigation of COP1 and the p53-associated functional network in hepatocellular carcinomas resulted in the development of new targeted therapeutics which use revealed that the antiproliferative effects of COP1 blockade suppressed neoplastic growth in both wild-type and mutant p53-containing liver tumors, without unwanted immune responses (60). 


\section{AIMS}

Taken together, these data suggest that huCOP1 is involved in the orchestrating of several cellular processes, and contributes to cellular stress response after genotoxic stress. The overexpression of COP1 in some human tumors suggests its possible in tumorigenesis.

In human keratinocytes, however, that are permanently exposed to many environmental factors, huCOP1 and its possible functions have not yet been investigated. Therefore, we aimed

- to characterize huCOP1 is expression in cultured human keratinocytes and in human epidermis,

- to investigate the effect of UVB on huCOP1 expression in human cultured keratinocytes and human epidermis,

- to elucidate the COP1-p53 interaction in human keratinocytes

- to determine the effect of UVB in COP1-silenced human keratinocytes together with UVB irradiation

- to characterize changes in COP1 expression during keratinocyte differentiation. 


\section{MATERIALS AND METHODS}

\subsection{Human tissue samples. Culturing of normal human keratinocytes and HaCaT keratinocytes}

Human tissue samples from various human organs were taken from patients who underwent different operations at the Department of Surgery, University of Szeged. Only noninvolved, healthy tissues were used for RNA isolation. All tissue samples were taken as described previously (67), with the patients' informed consent and the approval of the local committee .

Skin biopsies were obtained from healthy individuals undergoing plastic surgery; institutional approval and patient consent was given for experiments in adherence to the Helsinki guidelines. After removal of the subcutaneous tissue, skin biopsies were incubated overnight at $4{ }^{\circ} \mathrm{C}$ in Dispase solution (Grade II, Roche Molecular Biochemicals, Mannheim, Germany). The epidermis was separated from the dermis, and epidermal cells were prepared by using trypsin $(0.25 \%)$. Human epidermal keratinocytes were seeded in serum-free Keratinocyte Basal Medium (Gibco, Eggstein, Germany) supplemented with L-glutamine and antibiotic/antimycotic solution containing penicillin, streptomycin and amphotericin B (Sigma, Steinheim, Germany). Keratinocytes were grown at $37{ }^{\circ} \mathrm{C}$ in a $5 \% \mathrm{CO}_{2}$ atmosphere.

For the differentiation of keratinocyte cultures, normal human keratinocytes were cultured until 90-95\% confluence in the third passage. The culturing conditions were altered by increasing the calcium concentration in the culture media to $1.7 \mathrm{mM}$ (in the form of $\mathrm{CaCl}_{2}$ ) so as to promote terminal differentiation. Samples were taken at 0, 1, 2, 4, 6, 8 and 10 days after switching to the high calcium concentration medium.

The spontaneously immortalized human keratinocyte cell line, HaCaT, kindly provided by Dr. N. E. Fusening (Heidelberg, Germany), was maintained in high-glucose DMEM (Gibco, Eggstein, Germany), with $10 \%$ fetal bovine serum (HyClone, Perbio, Budapest, Hungary), supplemented with L-glutamine and antibiotic/antimycotic solution containing $100 \mathrm{U} / 1$ penicillin, $100 \mu \mathrm{l} / \mathrm{ml}$ streptomycin and amphotericin B (Sigma, Steinheim, Germany), at $37{ }^{\circ} \mathrm{C}$ in a $5 \% \mathrm{CO}_{2}$ atmosphere. 


\subsection{Immunocytochemistry, immunohistochemistry and immunofluorescence staining}

The immunocytochemistry of keratinocytes was performed as follows. Keratinocytes were grown on culture slides (BD Falcon, Bedford, MA, USA). The slides were fixed in $2 \%$ paraformaldehyde for $20 \mathrm{~min}$ and incubated with the primary antibody, rabbit polyclonal antihuman COP1 (Bethyl, Montgomery, USA), at a dilution of 1:5000 in a staining solution containing TBST (Tris-buffered saline containing 0.1\% Triton-X) (Sigma) and 0.5\% BSA (Sigma). Control slides were incubated with a mixture of COP1 Blocking peptide (Bethyl, Montgomery, USA) and rabbit polyclonal anti-human COP1 antibody (Bethyl) in a ratio of 3:1. After a rinse in TBS-Triton-X, sections were incubated with Alexa Fluor 488 labelled secondary anti-rabbit antibody (Invitrogen, Carlsbad, CA, USA) (dilution 1:800) for $3 \mathrm{hs,} \mathrm{and}$ were then stained with DAPI to detect the nuclei. For detection and analysis, Tissue Facs (Tissue Gnostics, Vienna, Austria) and an FV 1000 confocal microscope (Olympus, Germany) were used.

Immunohistochemical staining was performed as follows. Skin samples were obtained from healthy individuals after obtaining written consent. Formalin-fixed, paraffin-embedded skin tissue sections were dewaxed. Slides were placed in a slide rack and immersed in $500 \mathrm{ml}$ of $10 \mathrm{mM}$ citric acid buffer ( $\mathrm{pH}$ 6.0). After incubation in a microwave oven for $30 \mathrm{mins}$ at $700 \mathrm{~W}$, during which the incubation solution boiled for about 25 mins, the slides were rinsed with Tris-buffered saline (Sigma), containing $0.1 \%$ Triton-X (Reanal) for 15 mins. Nonspecific staining was prevented by preincubation with $0.5 \%$ bovine serum albumin diluted in Tris-buffered saline (Sigma) containing 0.1\% Triton-X (Reanal) for 30 mins at room temperature in a humid chamber. The slides were then incubated overnight at $4{ }^{\circ} \mathrm{C}$ in a humid chamber with the primary antibody; rabbit polyclonal anti-human COP1 antibody (Bethyl, Montgomery, TX, USA) was applied at 1:5000 dilution, and rabbit IgG (NeoMarkers) was used for isotype control staining. Slides were then incubated with a biotinylated secondary antibody (anti-rabbit $\operatorname{IgG}$ ) at 1:800 dilution for $1 \mathrm{~h}$ at room temperature, followed by incubation with horse radish peroxidase-conjugated streptavidin for $1 \mathrm{~h}$ at room temperature (both from Vectastain $\mathrm{ABC}$ Kit; Vector, Burlingame, CA), and at the end of the staining procedure peroxidase activity was detected by using 3,3-amino-9 
ethylcarbazole (Sigma) as substrate. Slides were counterstained with hematoxylin (Sigma). Tissue staining was visualized with a Zeiss Axio Imager microscope and photographed with a PixeLINK digital camera.

The immunofluorescence staining was performed as described above in connetion with the immunohistochemical staining until the incubation with the primary antibody. The slides were then incubated at $4{ }^{\circ} \mathrm{C}$ overnight in a humid chamber with the primary antibody; rabbit polyclonal anti-human COP1 antibody (Bethyl, Montgomery, TX, USA) was applied at 1:4000 dilution; control slides were incubated with a mixture of COP1 Blocking peptide (Bethyl, Montgomery, USA) and rabbit polyclonal anti-human COP1 antibody (Bethyl) in a ratio of 3:1. After a rinse in TBS-Triton-X, sections were incubated with Alexa Fluor 488labeled secondary anti-rabbit antibody (Invitrogen, Carlsbad, CA, USA) (dilution 1:500) for 3 hs, and were then stained with DAPI to detect the nuclei. For detection and analysis, Tissue Facs (Tissue Gnostics, Vienna, Austria) were used

\subsection{Constructs}

The pSUPER vector system (Oligoengine, Seattle, WA, USA) was used for the transient expression of short interfering RNAs (siRNAs) (61). Fifty-three-nt-long oligonucleotides of COP1 5'AGCTTcttgatttggccaatgtcaTTCAAGAGAtgacattggccaaatcaagttC3' (sense) and COP1 5'AgaactaaaccggttacagtAAGTTCTCTactgtaaccggtttagttcaaGAGCT3' (antisense) were cloned into the pSuperior.puro vector downstream of the $\mathrm{H} 1$ promoter.

\subsection{Nucleofection}

For silencing the expression of the COP1 gene, 7-8 x $10^{5}$ cells were transiently transfected with a COP1 siRNA producing construct (siCOP1), and another group of cells received the empty pSUPER vector $(\mathrm{Sp})$. DNA for transfection was purified with the Qiagen Plasmid Mini Kit (Qiagen, Hilden, Germany). Transfection was carried out by nucleofection (Amaxa, Cologne, Germany), and the Human Keratinocyte Kit (VPD-1002; Amaxa) was used for the nucleofection of keratinocytes (62). 
Nucleofection was carried out as follows: cultured keratinocytes were trypsinized for $10 \mathrm{~min}$ at room temperature, $1 \mathrm{ml}$ FBS was then added and the cells were centrifuged for 10 $\min$ at $1000 \mathrm{~g}$. The keratinocytes were next resuspended in $100 \mu \mathrm{l}$ of Keratinocyte Nucleofector Solution (Amaxa, Cologne, Germany) and $2 \mu \mathrm{g}$ of DNA was added. The mixture was transferred into an electroporation cuvette and placed into the nucleofector device (Amaxa, Cologne, Germany). Immediately after nucleofection, the keratinocyte suspension was transferred into 6-wellplates, containing $2 \mathrm{ml}$ of prewarmed keratinocyte medium. The culture medium was changed after $48 \mathrm{~h}$.

The transfection efficacy was determined by analyzing the expression of green fluorescent protein (GFP) with a FACScalibur flow cytometer (Becton Dickinson, San Jose, CA, USA) and CellQuest software (Becton Dickinson) and the mean fluorescence intensity of the expressing construct was measured. The average efficacy of transfection was $\sim 60 \%$.

\subsection{UVB irradiation (FS20 lamp, excimer laser)}

An FS20 lamp (Westinghouse, Pittsburgh, PA, USA) was used as a radiation source for UVB; this instrument emits radiation of wavelength ranging between 250 and $400 \mathrm{~nm}$, peaking at $290 \mathrm{~nm}(37,63,64)$. Our radiometry system was an Optronic OL754 spectroradiometer, and for calibration we used an OL752-12D2 lamp. To determine the highest nonlethal dose of UVB, we irradiated keratinocytes with $0,10,20,40$ and $60 \mathrm{~mJ} / \mathrm{cm}^{2}$ UVB light, and the viability of the treated cells was analyzed by MTT assay 24 and 48 hs after irradiation. The $40 \mathrm{~mJ} / \mathrm{cm}^{2}$ found to be the highest nonlethal UVB dose was therefore used in subsequent experiments. For irradiation, the medium was removed, $500 \mu \mathrm{PBS}$ was added and keratinocytes were irradiated with 10,20 or $40 \mathrm{~mJ} / \mathrm{cm}^{2}$ UVB. After irradiation, 2 $\mathrm{ml}$ of serum-free keratinocyte medium was added to the cells. Samples for mRNA expression experiments were collected $12 \mathrm{hs}$ after irradiation, while samples for protein expression experiments were collected $24 \mathrm{hs}$ after irradiation.

The $308 \mathrm{~nm}$ excimer laser, a coherent monochromatic pulse-mode UVB XeCl laser was utilized for human skin irradiation (63). The minimal erythema dose (MED) was 
determined with increasing doses of $308 \mathrm{~nm}$ UVB, and 2 MED was used for irradiation on a non-sun-exposed area of the body in subsequent experiments. Skin biopsies $(6 \mathrm{~mm})$ were taken from irradiated and non-irradiated skin 24 and 48 hs after irradiation with the patients's informed consent and the approval of the local ethics committee.

\subsection{Reverse transcription and real-time RT-PCR}

Total RNA was isolated from cell cultures with the TRIzol reagent (Life Technologies, Carlsbad, CA, USA) $12 \mathrm{~h}$ after UVB irradiation, following the instructions of the manual. cDNA was generated with oligo(dT) and random hexamer primers from $1 \mu \mathrm{g}$ of RNA, using the iScript ${ }^{\mathrm{TM}}$ cDNA Synthesis Kit (Bio-Rad Laboratories, Hercules, CA, USA) in a final volume of $20 \mu \mathrm{l}$. After reverse transcription, the real-time RT-PCR was performed to compare the abundance of COP1 mRNA using TaqMan ${ }^{\circledR}$ Gene Expression Assays (Applera, Foster City, CA, USA) for the RFWD2 (cat. No. Hs00375437_m1) and for p53 (cat. No. Hs01034249_m1). The abundance of the gene of interest transcript was normalized to the expression of $18 \mathrm{~S}$ ribosomal RNA for each examined sample. The primers for $18 \mathrm{~S}$ were: $18 \mathrm{~S}$ RNA forward: CGGCTACCACATCCAAGGAA, 18S RNA reverse: GCTGGAATTACCGCGGCT, 18S RNA TaqMan probe: TexRedTGCTGGACCAGACTTGCCCTC-BHQ-1 (Integrated DNA Technologies, Coralville, IA, USA). The RT-PCR reactions were performed by using iQ Supermix (Bio-Rad Laboratories, Hercules, CA, USA) in an iCycler (Bio-Rad Laboratories, Hercules, CA, USA) (65) .

\subsection{Western blot analysis}

Cells were washed twice with PBS, and protein was extracted by resuspending the cells in a solution containing 12.5\% $0.5 \mathrm{mM}$ Tris (pH 6.8), 2.5\% $200 \mathrm{mM}$ EDTA, 15\% 10\% SDS, $70 \% \mathrm{H}_{2} \mathrm{O}, 10 \mu \mathrm{l}$ of protease inhibitor and $50 \mu \mathrm{l}$ of $\beta$-mercaptoethanol per $\mathrm{ml}$ (all chemicals were obtained from Sigma-Aldrich) $24 \mathrm{~h}$ after UVB irradiation. Protein lysates were incubated for $5 \mathrm{~min}$ on ice and, after a 30-sec hard vortexing, cell debris was removed by centrifugation at $10000 \mathrm{~g}$ for $10 \mathrm{~min}$ at $4{ }^{\circ} \mathrm{C}$. In order to verify the equivalent loading of 
proteins in the wells, the following procedure was carried out: based on the OD280-measured density, the protein concentration of each sample was calculated and the samples were then run on $10 \%$ sodium dodecylsulfate-polyacrylamide gel (SDS-PAGE). The gels were stained with Coomassie Brillant Blue (CBB, Sigma-Aldrich), dried and scanned, and all loaded lanes were analyzed by densitometry. The amounts of the loaded protein samples were further corrected and checked again on SDS-PAGE (66) .

For western-blot analysis, equal amounts of proteins were run on SDS-PAGE and then transferred to nitrocellulose membrane (Bio-Rad Laboratories, Hercules, CA, USA). Membranes were blocked by incubation in Tris-buffered saline $(150 \mathrm{mM} \mathrm{NaCl}, 25 \mathrm{mM}$ Tris, pH 7.4) containing $0.05 \%$ Tween 20 (Sigma-Aldrich) and 3\% non-fat dry milk (Fluka Chemie AG, Neu-Buchs, Switzerland) for 2 hs at room temperature and subsequently incubated overnight at $4{ }^{\circ} \mathrm{C}$ with purified mouse monoclonal anti-human p53 antibody (Calbiochem, Darmstadt, Germany), rabbit polyclonal anti-human COP1 antibody (Bethyl, Montgomery, TX, USA), and rabbit monoclonal anti-actin antibody (Sigma-Aldrich). Alkaline phosphataseconjugated goat anti-mouse IgG (Sigma-Aldrich) and anti-rabbit IgG (Sigma-Aldrich) were used as secondary antibodies at 1:2000 dilution in the blocking buffer and membranes were incubated for $2 \mathrm{hs}$ at room temperature. The blots were developed by using 5-bromo-4-chloro3-indolyl phosphate/nitroblue tetrazolium as substrate (BCIP/NBT, Sigma-Aldrich, Saint Louis, MO, USA). 


\section{RESULTS}

\subsection{COP1 expression and subcellular localization in cultured normal human} keratinocytes and HaCaT cells

Only limited information is available on COP1 expression in normal human tissue samples, and we therefore set out to determine COP1 expression in a set of RNA samples isolated from various human organs. We were especially interested in whether COP1 was expressed in the epidermis.

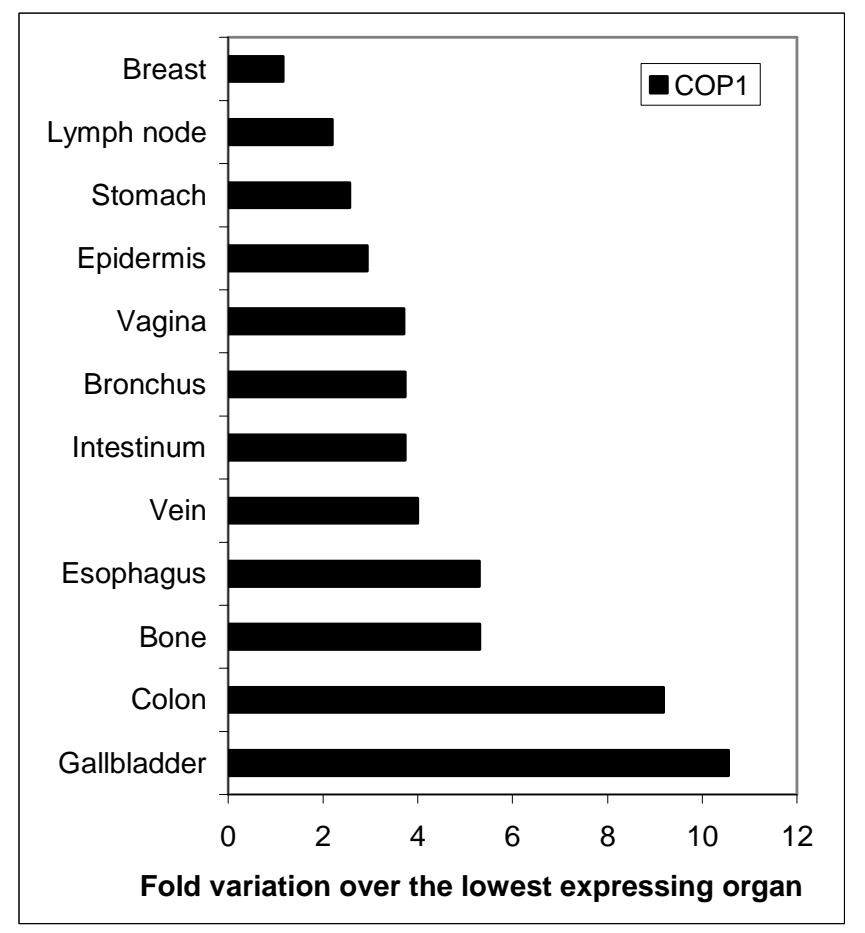

Figure 5. COP1 is expressed in various human organs. Total RNA was isolated from tissue samples from various human organs and the COP1 mRNA abundance was detected by real-time RT-PCR.

COP1 expression was detected in all of the studied organ types. Interestingly, the level of expression differed to a great extent in the different organs. The lowest level of COP1 mRNA 
was detected in the breast sample, in agreement with earlier literature data. The highest level was seen in the gallbladder, 16-fold higher than in the breast.

We also demonstrated by RT-PCR and western blot hybridization assays that normal human cultured keratinocytes express COP1 mRNA and protein (Fig. 6). COP1 mRNA was detected both in normal human keratinocytes and in HaCaT keratinocytes. In HaCaT keratinocytes the amount of COP1 mRNA was higher. As demonstrated by western blot analysis, HaCaT cells also expressed higher levels of COP1 protein compared to normal human keratinocytes. To examine the role of COP1 as a regulator of p53 in keratinocytes, we used normal keratinocytes for our subsequent investigations. Since HaCaT cells express an extremely high and stable level of p53 protein, HaCaT cells did not seem to be a good model cell to study COP1-p53 interactions.

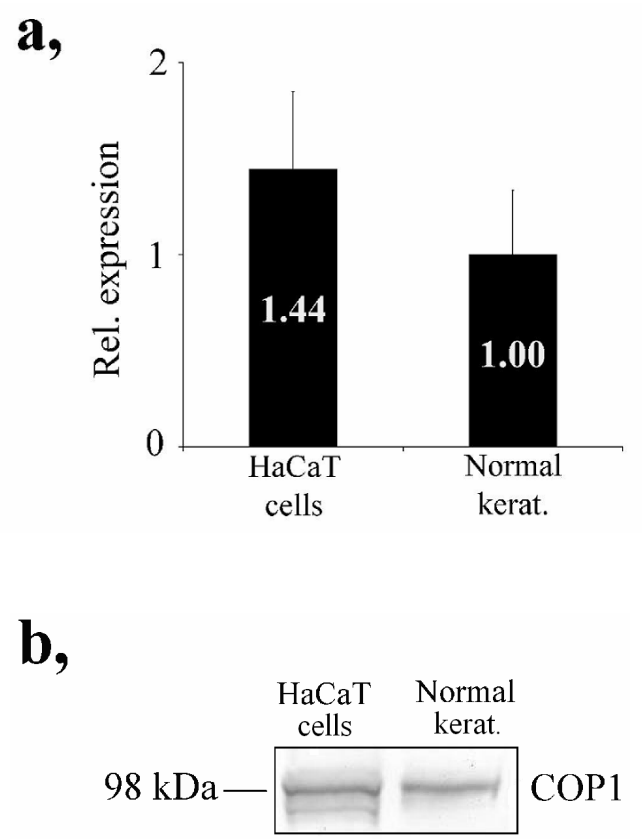

Figure 6. COP1 expression in HaCaT keratinocytes and normal human keratinocytes. (a) COP1 mRNA was detected both in HaCaT keratinocytes and in normal human keratinocytes. The HaCaT keratinocytes exhibited a somewhat higher amount of COP1 mRNA $(n=3)$. (b) COP1 protein was also detected both in normal human keratinocytes and in immortalized HaCaT cells: both cell types expressed high levels of COP1 protein. 
We next determined the subcellular localization of COP1 protein in cultured normal human keratinocytes. COP1 protein was detected both in the cytoplasm as well as in the nucleus in unstressed keratinocytes compared to control cells incubating with blocking peptid before staining. The bulk of the immunofluorescence staining of COP1 was restricted to the nucleus, and only mild positivity was visible in the cytoplasm (Fig. 7).
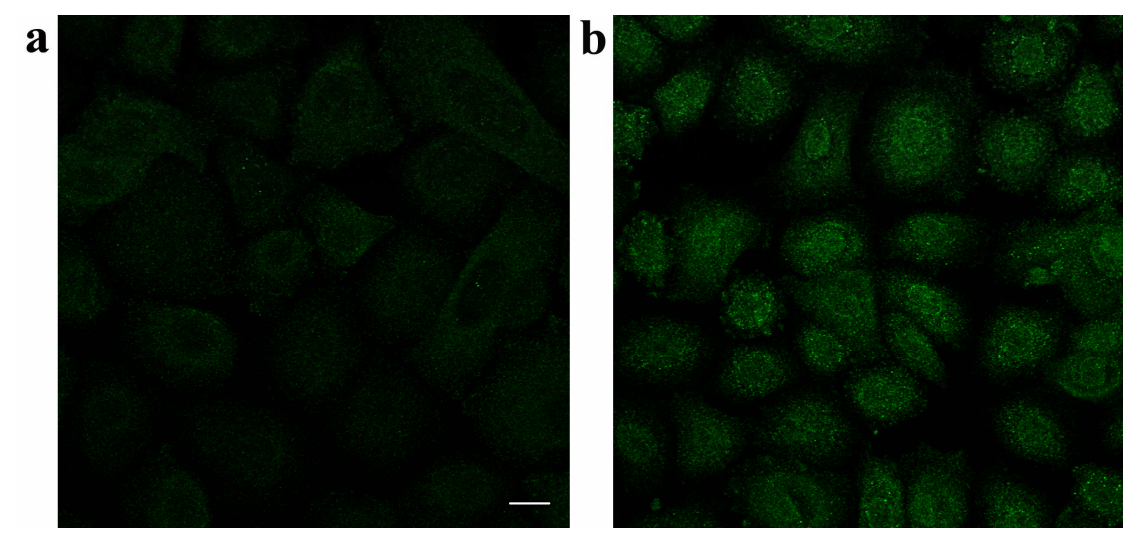

Figure 7. Subcellular localization of COP1 in normal human keratinocytes. Keratinocytes were grown on culture slides. Slides were fixed in $2 \%$ paraformaldehyde and incubated with (a) a mixture of COP1 blocking peptide and anti-COP1 antibody in a ratio of 3:1 as control for immunostaining; (b) anti-COP1 antibody to determine COP1 protein. An FV 1000 confocal microscope was used for detection. (a) Staining was not detected on control slides, (b) COP1 specific staining was detected both in the nucleus and in the cytoplasm in the keratinocytes. A marked amount of COP1 protein is seen in the nuclei of COP1 stained cells compared to the nuclei of the cells on the control slide. Bar $=$ $25 \mu \mathrm{m}$.

\subsection{COP1 and p53 expression in UVB-irradiated keratinocytes}

COP1 mRNA expression decreases after UVB irradiation in keratinocytes. For further investigation of huCOP1 in epidermal cells, we performed in vitro and in vivo experiments. To determine the highest nonlethal dose of UVB, we irradiated keratinocytes with $0,10,20,40$ and $60 \mathrm{~mJ} / \mathrm{cm}^{2} \mathrm{UVB}$ light. The dose-dependent changes in COP1 mRNA expression were detected (Fig. 8.) and the viability of the irradiated cells was analyzed by MTT assay. The 40 $\mathrm{mJ} / \mathrm{cm}^{2}$ found to be the highest nonlethal UVB dose, $70-80 \%$ of the treated cells in the culture survived it, therefore we applied this dose for the irradiation of subconfluent keratinocyte cultures. 


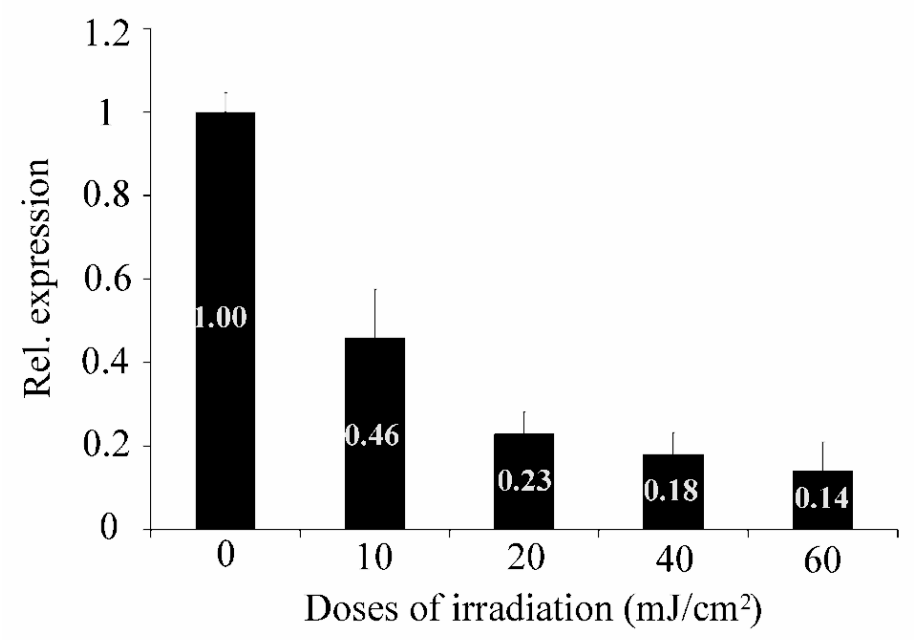

Figure 8. Dose-dependent changes of COP1 mRNA expression in keratinocytes after UVB irradiation. COP1 mRNA levels were determined by real-time RT-PCR. Normal human keratinocytes were irradiated with increasing doses of $\operatorname{UVB}\left(0,10,20,40\right.$ and $\left.60 \mathrm{~mJ} / \mathrm{cm}^{2}\right)$ and harvested $12 \mathrm{hs}$ after UVB exposure. COP1 mRNA expression was presented after normalization to $18 \mathrm{~S}$. The relative huCOP1 expression in the irradiated cells was compared with that of non-irradiated control cells. Values are the means $\pm \mathrm{SE}$ of the results of three independent experiments.

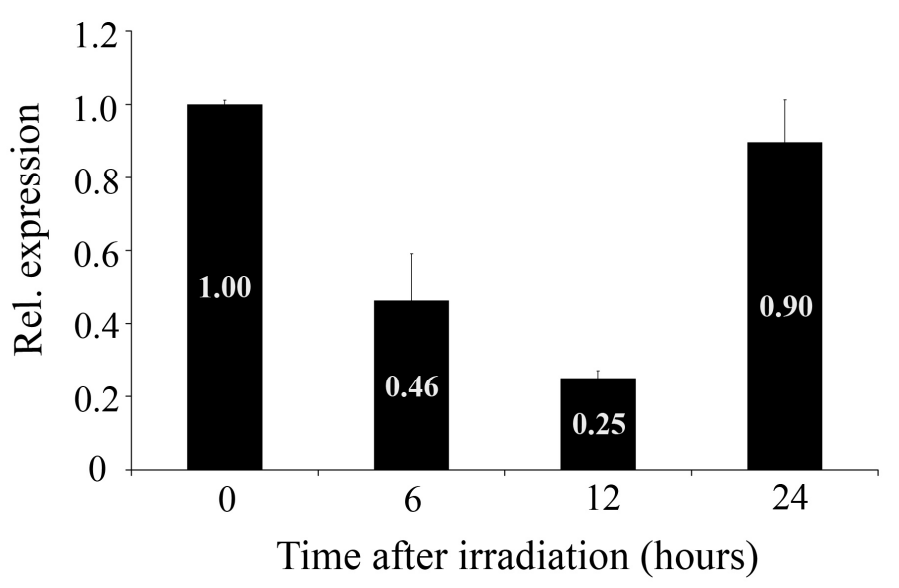

Figure 9. Time-course of COP1 mRNA expression changes in keratinocytes after UVB irradiation. The COP1 mRNA abundance was detected at various time points following $40 \mathrm{~mJ} / \mathrm{cm}^{2} \mathrm{UVB}$ exposure. Relative huCOP1 expression was compared with that expression of the $0 \mathrm{~h}$ sample. Values are the means $\pm \mathrm{SE}$ of the results of three independent experiments. 
To measure the kinetic changes in COP1 mRNA expression, keratinocytes were harvested at various time points $(0,6,12$ and $24 \mathrm{hs})$ after exposure to $40 \mathrm{~mJ} / \mathrm{cm}^{2} \mathrm{UVB}(\mathrm{n}=3)$ and the COP1 mRNA expression was determined by real-time RT-PCR. The COP1 mRNA levels started to decline within $6 \mathrm{~h}$ after UVB exposure, were at an almost undetectable level after $12 \mathrm{hs,}$ and then slowly increased, approaching the normal value at $24 \mathrm{~h}$ (Fig. 9).

UVB irradiation decreases the COP1 protein level in keratinocytes. We determined the abundance of COP1 and p53 proteins in keratinocytes $(n=6)$ at various time-points $(0,6,12$ and $24 \mathrm{hs}$ ) after irradiation with $40 \mathrm{~mJ} / \mathrm{cm}^{2}$ UVB. The UVB-induced a dose-dependent decreases in COP1 protein are shown in Fig. 10. In contrast with COP1 mRNA, COP1 protein reached its minimum level at $24 \mathrm{~h}$ after UVB treatment. The p53 protein level was already increased $6 \mathrm{hs}$ after UVB exposure and remained at high levels throughout the 24-h experimental period.

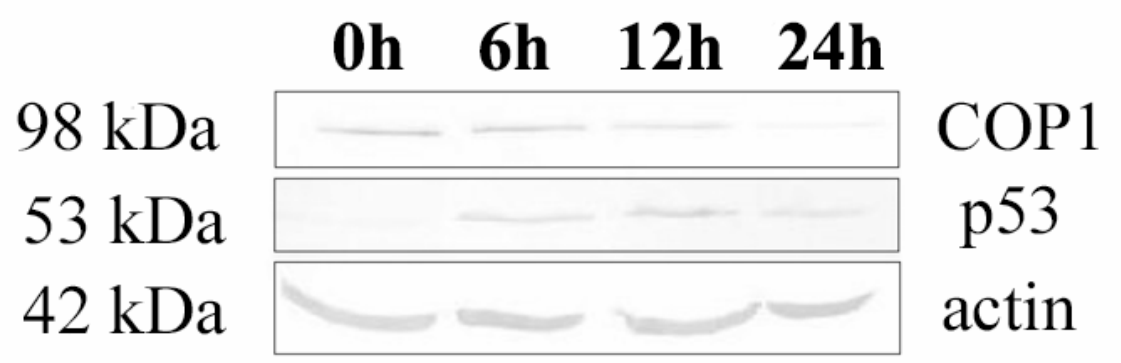

Figure 10. COP1 and p53 protein expression in keratinocytes after UVB irradiation. Normal human keratinocytes were irradiated with $40 \mathrm{~mJ} / \mathrm{cm}^{2}$ UVB light. Cells were harvested 6, 12 and $24 \mathrm{hs}$ after UVB exposure. The COP1 and p53 protein levels were assessed by western blotting. Identical levels of $\alpha$-actin indicate equal loading of samples.

To measure the kinetic changes in p53 mRNA expression, keratinocytes were harvested at various time points $(0,6,12$ and $24 \mathrm{hs})$ after exposure to $40 \mathrm{~mJ} / \mathrm{cm}^{2} \mathrm{UVB}(\mathrm{n}=3)$ and the p53 mRNA expression was determined by real-time RT-PCR (Fig. 11). In contrast with the COP1 mRNA, the p53 mRNA levels were not significantly changed during $12 \mathrm{hs}$ 
after irradiation, but a marked increase was apparent at $24 \mathrm{~h}$ after UVB exposure. These results were in agreement with previously published data on the UV-induced p53 expression in keratinocytes.

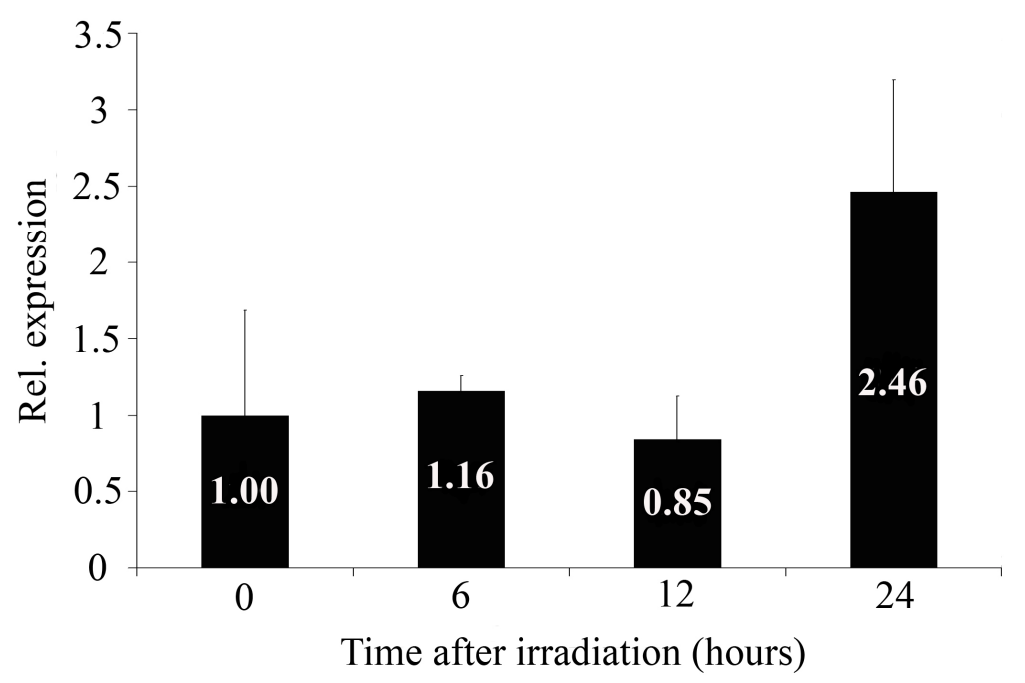

Figure 11. The time-dependent changes in p53 mRNA expression in keratinocytes after UVB irradiation. p53 mRNA level was detected at various time points following a $40 \mathrm{~mJ} / \mathrm{cm}^{2} \mathrm{UVB}$ exposure. The relative COP1 expression was compared with that of the $0 \mathrm{~h}$ sample. Values are the means $\pm \mathrm{SE}$ of the results of three independent experiments.

UVB irradiation alters the subcellular localization of COP1 protein in keratinocytes. Immunofluorescence staining of COP1 demonstrated that treatment with $40 \mathrm{~mJ} / \mathrm{cm}^{2} \mathrm{UVB}$ affects the subcellular distribution of the protein. Following UVB treatment, a substantial proportion of the COP1 protein was detected in the cytoplasm. This was in stark contrast with the untreated cells, in which COP1 was predominantly localized in the nucleus. However, in the cytoplasm marked perinuclear COP1 staining in the UVB-irradiated keratinocytes was apparent (Fig. 12). 


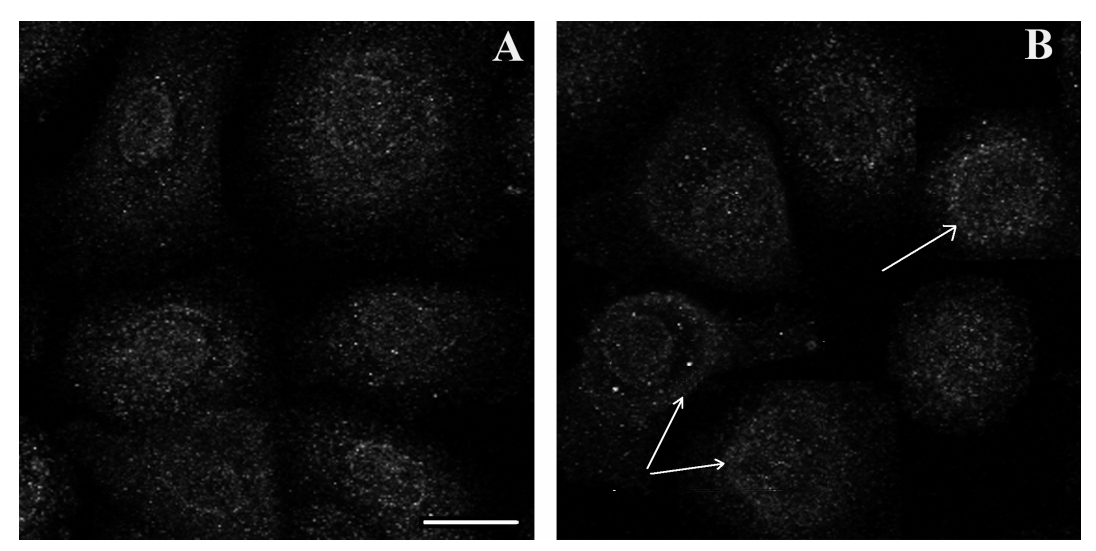

Figure 12. The subcellular localization of COP1 is changed after UVB irradiation. For better visualization, grayscale images of COP1 staining are presented. A reduced staining of COP1 was apparent in the cytoplasm and the nucleus of the keratinocytes after UVB irradiation (B) as compared to the untreated cells (A), and an excess amount of COP1 protein formed a perinuclear ring (white arrows) in the cytoplasm. For detection an FV 1000 confocal microscope was used. Bar $=25 \mu \mathrm{m}$.

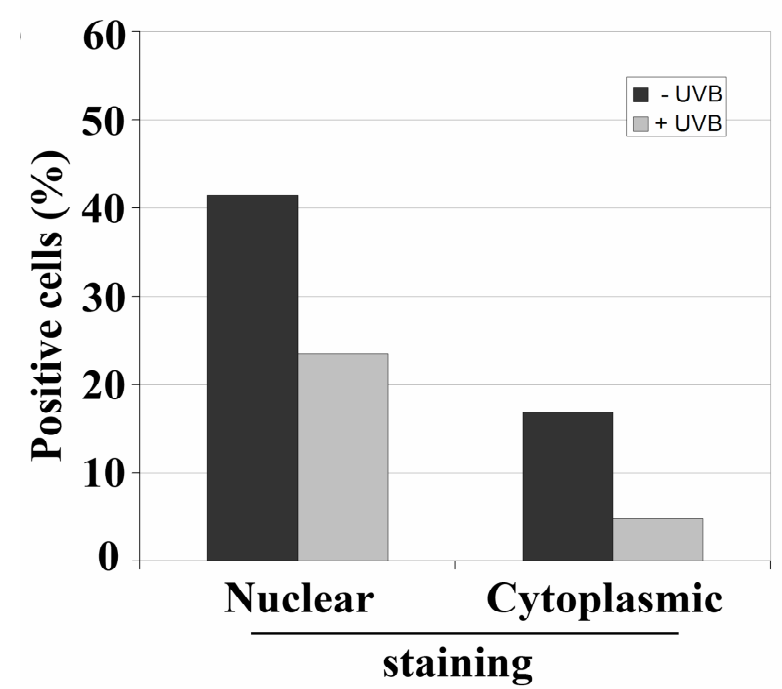

Figure 13. Semiquantitative analysis of immunofluorescence staining was carried out with a Tissue Facs device. To measure the extent of the nuclear and the cytoplasmic staining of COP1, the Tissue Quest Analysis program was used. The level of COP1-specific staining was compared with that for control cells stained with a mixture of COP1 blocking peptide and anti-COP1 antibody in a ratio of $3: 1$. The mean of the results of three independent experiments is shown. 
Semiquantitative analysis of immunofluorescence staining demonstrated that treatment with $40 \mathrm{~mJ} / \mathrm{cm}^{2} \mathrm{UVB}$ affected the COP1 expression both in the nuclei and in the cytoplasm, to approximately the same extent (Fig. 13.).

\subsection{Up-regulated p53 protein expression is further increased by UVB irradiation in gene-specifically silenced COP1 cells}

Early data on COP1 expression in mammalian cells indicated that it is a critical negative regulator of 553 protein. UVB irradiation and COP1 silencing have an additive effect on the induction of p53 expression. To gain further insight into the p53 regulatory function of COP1 in keratinocytes, we determined p53 protein levels in cells in which the expression of COP1 was specifically silenced by siCOP1 RNA. Western-blot experiments revealed that the expression of shCOP1 RNA resulted in the depletion of COP1 protein and significant upregulation of p53 protein as compared with the mock-transfected cells (Fig. 14).

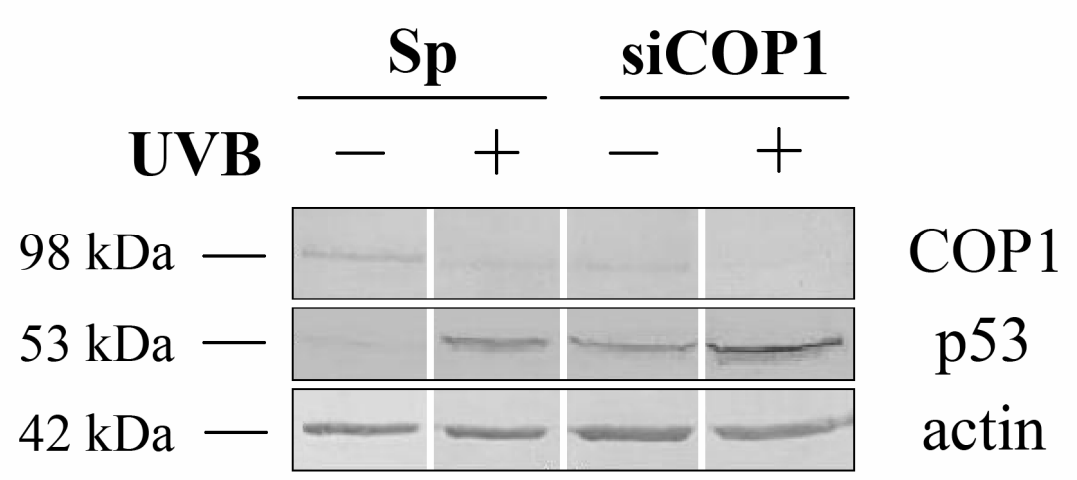

Figure 14. Silencing of COP1 mRNA expression induces p53 protein accumulation in keratinocytes and UVB irradiation induces further p53 protein accumulation in siCOP1 nucleofected cells. Normal cultured keratinocytes were nucleofected with the indicated siRNAs, and two groups of cells were irradiated with $40 \mathrm{~mJ} / \mathrm{cm}^{2}$ UVB $72 \mathrm{hs}$ after nucleofection. Cells were harvested $24 \mathrm{hs}$ after irradiation, and the changes in level of COP1 and p53 protein were detected by western blotting. Identical levels of $\alpha$-actin indicate equal loading of samples. The non-irradiated COP1-silenced cells (siCOP1) expressed a lower level of COP1 protein and a higher level of p53 protein as compared with nonirradiated mock-transfected cells $(\mathrm{Sp})$. UVB irradiation of COP1-silenced cells (siCOP1) resulted in a further increase in 553 protein level as compared with the irradiated mock-transfected cells (Sp), while the level of COP1 protein was lowest in the irradiated COP1-silenced keratinocytes. 
We next investigated the effect of UVB irradiation in siCOP1-transfected keratinocytes treated with $40 \mathrm{~mJ} / \mathrm{cm}^{2}$. In these experiments, we monitored the intracellular levels of COP1 and p53 proteins $24 \mathrm{hs}$ after irradiation. We demonstrated that UVB irradiation further decreased the level of COP1 protein, whereas the expression of p53 exhibited an additional increase (Fig. 14). We concluded that COP1 silencing and UVB irradiation have additive effects on p53 protein accumulation in normal human keratinocytes.

\subsection{COP1 expression in normal and UVB-irradiated human skin}

COP1 protein expression was detected in normal human skin with immunohistochemistry (Fig. 15). COP1 expression was the most prevalent in the stratum granulosum of the epidermis, and mild positivity was also apparent in the basal layer. The staining was strongest in the cytoplasm of the epidermal keratinocytes.

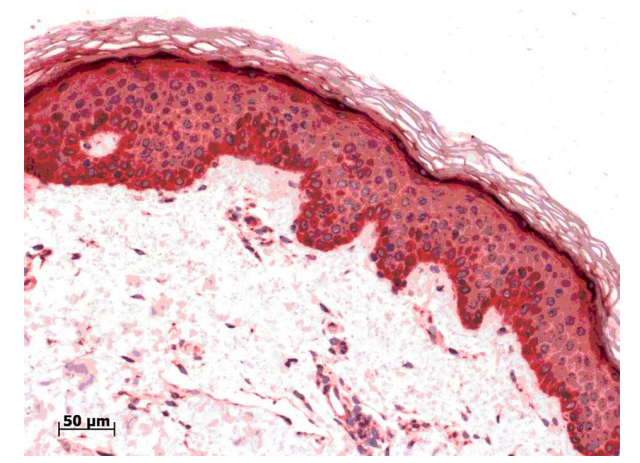

Figure 15. Immunohistochemical staining of COP1 in normal human skin. When sections of normal human skin biopsies were labeled with polyclonal COP1 antibody, a mildly positive basal layer and an extremely highly positive granular layer of COP1-specific staining were seen. Control staining was performed in the absence of the antibody. Bar represents $50 \mu \mathrm{m}$.

The expression of COP1 protein in normal human skin was also investigated by immunofluorescence labeling. In agreement with the immunohistochemistry, we found mild cytoplasmic staining in the basal layer of the epidermis and strong cytoplasmic staining was present in the granular layer (Fig. 16). 


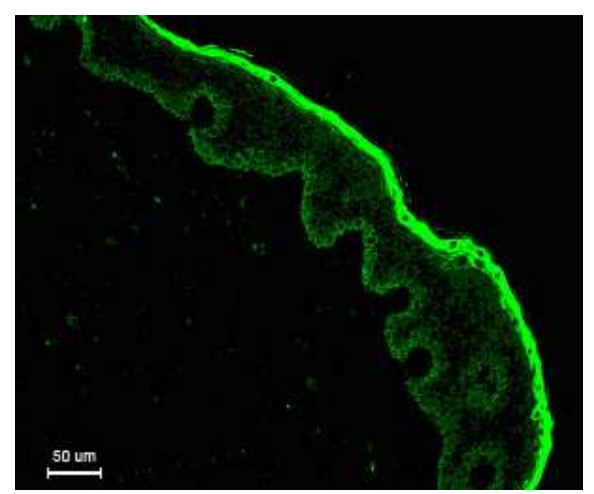

Figure 16. Immunofluorescence staining of COP1 in normal human skin. Cryosections of normal human skin biopsies were labeled with polyclonal COP1 antibody: COP1 was expressed at low levels in the basal layer, and at a high level in the granular layer. Bar represents $50 \mu \mathrm{m}$.

Next our aim was to study the effect of UVB irradiation on COP1 expression in human skin. Normal human skin was irradiated with 2 MED and skin biopsies were taken 24 and $48 \mathrm{hs}$ after irradiation (Fig. 17).

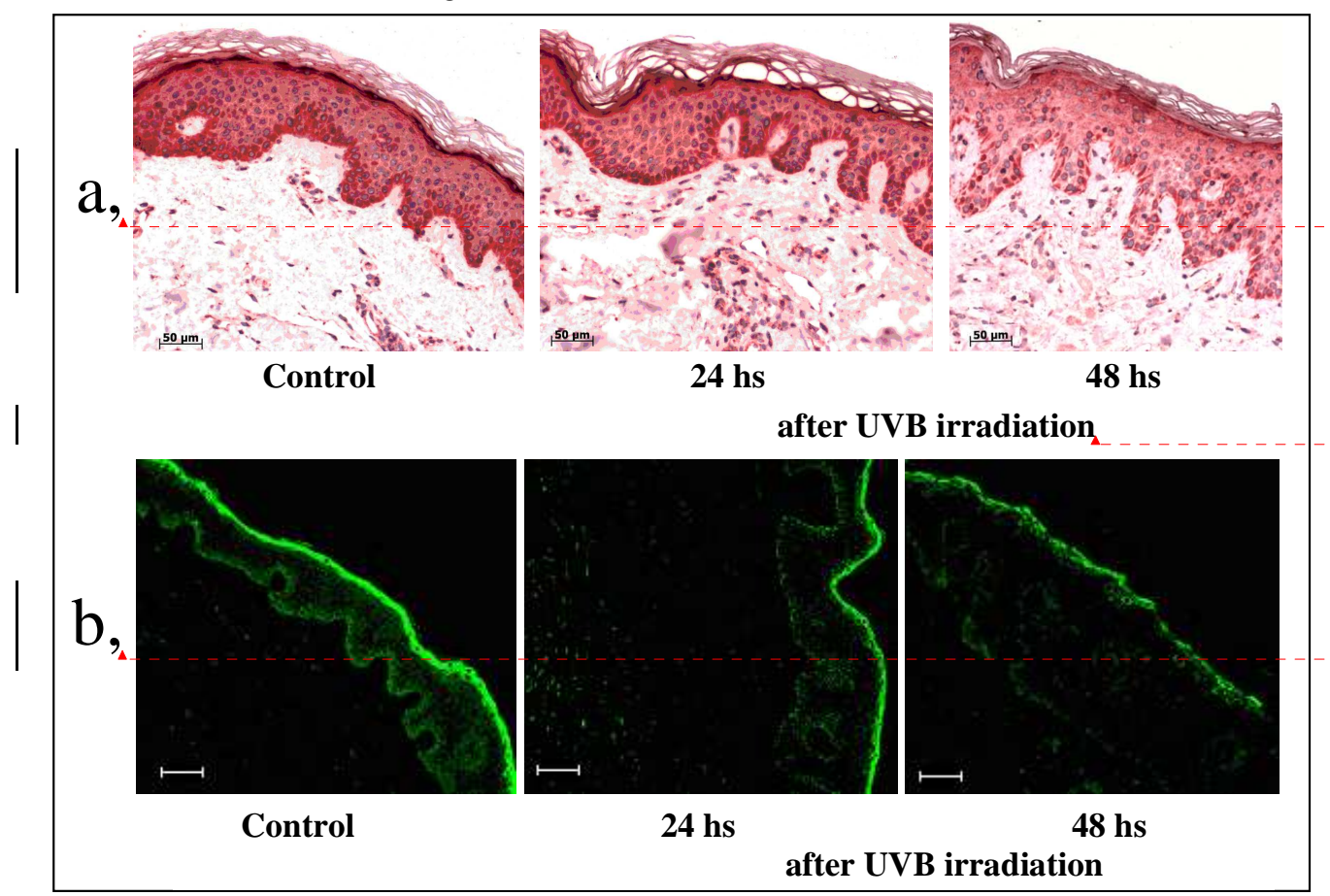

Formázott: Betűtípus: 24 pt

Formázott: Betütípus:

Félkövér

Formázott: Betűtípus: 24 pt

Figure 17. Immunohistochemistry (a) and immunofluorescence stainings (b) of COP1 in UVBirradiated human skin. Human skin was irradiated with 2 MED (mean $400 \mathrm{~mJ} / \mathrm{cm}^{2}$ ). Skin biopsies were taken from non-irradiated (control) and irradiated skin 24 and 48 hs after irradiation. Bar represents $50 \mu \mathrm{m}$. 
Both immunohistochemistry and immunofluorescence stainings indicated changes in COP1 expression in UVB-irradiated normal human skin. The COP1 expression was already decreased in both the stratum basale and the stratum granulosum $24 \mathrm{hs}$ after the irradiation and was even lower $48 \mathrm{hs}$ following the irradiation. These results suggest that the COP1 expression changes are part of the long-term stress response of human skin in response to UVB irradiation.

\subsection{The level of COP1 protein in differentiating keratinocytes}

The pattern of COP1 expression in the human epidermis prompted us to further analyze the changes in expression of COP1 in in vitro differentiating keratinocytes and to investigate the COP1-p53 relationship during differentiation. For the modeling of keratinocyte differentiation, we cultured keratinocytes in serum-free keratinocyte medium, with the addition of $1.7 \mathrm{mM}$ calcium (Fig.18). To monitor the differentiation of keratinocytes, the expression of involucrin, a well-known differentiation marker, was investigated through western blotting, and we found an extremely high overexpression of the protein in parallel with the aging of the culture. p53 protein was expressed at a low level in the differentiating keratinocytes and did not exhibit change with time in the experimental period. In contrast, the initiation of differentiation resulted in a definitive decrease in COP1 protein in the keratinocyte culture; this decrease was already obvious 2 days after the induction of the differentiation. In parallel with this, we detected similar changes in COP1 expression in cultured normal human keratinocytes without calcium addition: the COP1 expression displayed a gradual decrease in cultured keratinocytes (data not shown). 


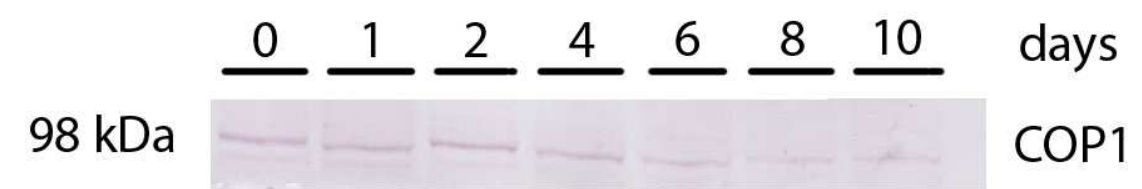

$53 \mathrm{kDa} \quad \mathrm{p53}$

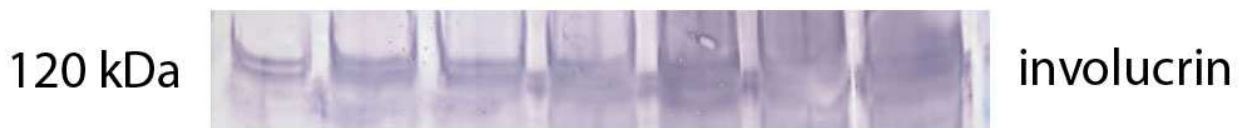

$42 \mathrm{kDa}+\ldots a c t i n$

Figure 18. Expression of p53 and COP1 proteins during in vitro induced keratinocyte differentiation. Keratinocytes were induced to differentiate by a high calcium culture medium, harvested at the indicated time points and analyzed by western blotting for the proteins indicated. $0 \mathrm{~d}$ : exponentially growing cells in low calcium medium; $1-10 \mathrm{~d}$ : cells were cultured with a high concentration $(1.7 \mathrm{mM})$ of calcium ion. The expression of involucrin, a well-characterized differentiation marker, was detected to follow the differentiation of keratinocytes in the culture. 


\section{DISCUSSION}

COP1, the Constitutive Photomorphogenic Protein 1, is well conserved across species: it is essential for normal photomorphogenesis in plants $(6,7,9)$, and it has also been detected in mammalian cells $(13,15,17,19)$. COP1 acts as a multifunctional ubiquitin ligase in plants and targets key transcription factors for proteasome-dependent degradation $(8,10,15,68,69)$. Oravecz et al. reported that, in stark contrast to its negative regulatory function in the visible part of the spectrum, AtCOP1 acts as a positive regulator of UVBinduced signaling in plant cells, and UVB irradiation promotes the accumulation of AtCOP1 in the nucleus (70). These data indicate that AtCOP1 is a multifunctional E3 ligase, and both its subcellular distribution and its substrate specificity are wavelength-specific. The striking degree of structural conservation of huCOP1 with its Arabidopsis counterpart suggested the possibility of a functional similarity too (13). Similarly to AtCOP1, MmCOP1 (13) and huCOP1 are also present in the nucleus and the cytoplasm of cells (15). The initial characterization showed that MmCOP1 (rodent), like its plant counterpart, is indeed involved in ubiquitination and is itself a substrate of its own ubiquitination activity (15). The huCOP1 ubiquitin ligase has been found to promote ubiquitin-dependent p53 degradation directly by the $26 \mathrm{~S}$ proteasome $(43,45)$. This process is independent of Mdm2 or Pirh2, which are also known to interact with and negatively regulate p53 $(19,31)$. The expression of huCOP1 has been detected in many cell lines (19), but its role in human cells is still not well characterized.

Our aim was therefore to investigate in detail the expression and function of huCOP1 in keratinocytes, the cell type most exposed to UVB irradiation. Our investigations showed that $\mathrm{COP} 1$ protein is present in human keratinocytes and immortalized $\mathrm{HaCaT}$ keratinocytes. As $\mathrm{HaCaT}$ cells express an enormously high and stable p53 protein level carrying mutations that alter the p53 function, it was not worth while to investigate the relationship of COP1 and p53 in this cell line (71). COP1 protein is predominantly expressed in the nucleus of keratinocytes under unstressed conditions, and milder positivity is detected in the cytoplasm. It was previously demonstrated by others that, in an unstressed condition, p53 also shows a predominantly nuclear localization, and it is monoubiquitinated by $\operatorname{Mdm} 2(33,45)$. Following monoubiquitination, p53 may remain in the nucleus to be polyubiquitinated by 
Mdm2, Pirh2, COP1 or a complex of these proteins, or it may be exported to the cytoplasm (43). All these processes explain the high nuclear expression of COP1 protein. The nuclear export of p53 promotes its cytosolic accumulation where it is further polyubiquitinated by Mdm2, Pirh2, COP1 or a complex of these proteins and degradated in the cytosolic 26S proteasome (43) . Based on our data, we propose a potential model for COP1-p53 regulation in unstressed keratinocytes (Fig. 19).

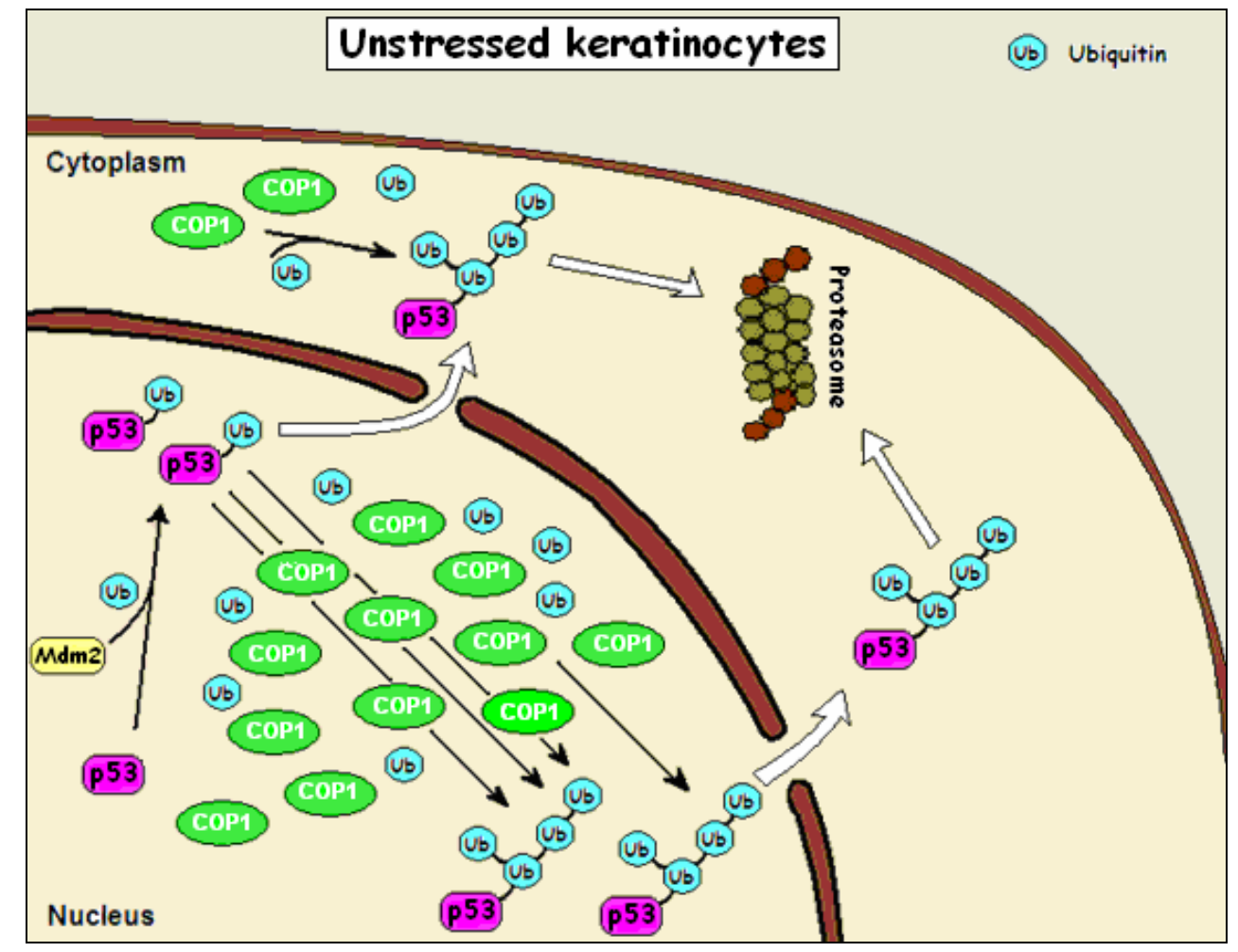

Figure 19. COP1 protein is present in a high amount in the cytoplasm and the nucleus of keratinocytes. In an unstressed condition, the protein functions as a ubiquitin ligase, and it results the polyubiquitination of $\mathrm{p} 53$, as it is well-known in plant and mammalian cells. The polyubiquitinated p53 molecule is degradated in proteasomes resulting in a low level of p53 protein.

The comparison of the COP1 mRNA levels in various human tissues revealed that the epidermis expressed a significantly lower level of COP1 mRNA than the colon or gallbladder, but it was higher as compared with the breast tissue, where it was almost undetectable. A weak COP1 signal in normal breast tissue has already been described, whereas in breast 
adenocarcinoma the overexpression of the protein was detected. The same was demonstrated in ovarian adenocarcinomas, where the positive COP1 signal was present only within the malignant cells, and the stromal compartment or normal ovarian tissues were negative (59). This is concomitant mainly with a decrease in steady-state wild-type p53 protein levels or p53-dependent transcription, indicating that one of the major roles of COP1 is to repress p53dependent tumor suppression. The fact that we detected COP1 in the epidermis affirmed our aim of investigating its physiological functions in normal skin.

In order to elucidate the biological function of COP1 in the major constituent cell type of the epidermis, the keratinocytes, we investigated its expression in response to genotoxic stress such as UVB light. Although UVB light is the most prominent genotoxic stress for keratinocytes, its effect on COP1 expression has not yet been investigated in these cells. Previously, it was shown that COP1 protein expression is decreased following ionizing treatment (IR) treatment in wild-type p53-expressing U2OS osteosarcoma cells and fibroblasts (72). It has also been demonstrated that a decreased abundance of COP1 protein can not be attributed to a decrease in COP1 mRNA level. Short IR treatment leads to the downregulation of COP1 protein by an ATM-kinase-mediated pathway and it includes the site-specific phosphorylation of COP1 followed by auto-ubiqitination and degradation. Another previous investigation has shown that treatment with UV irradiation results in a COP1 protein decrease in NIH3T3 mouse fibroblast cells (54). In the present study, we found that the COP1 mRNA level exhibited a biphasic response to UVB. It was decreased early after UVB irradiation, and a slow increase was observed after $12 \mathrm{hs}$. In contrast with the biphasic mRNA profile, the COP1 protein level displayed a steady slow, but marked decrease. In a previous study, UVC stress induced an increase in COP1 protein level in both HeLa and U2OS cells, although the COP1 mRNA showed a biphasic response characterized by a downregulation at early timepoints followed by a subsequent upregulation (58). These observations indicate that UV irradiation differentially affects COP1 protein levels in human keratinocytes and cancer cells.

Several data suggest that, besides its expression changes, the function of COP1 may also be altered by its intracellular movement $(11,15,73)$. The first data on COP1 intracellular localization revealed that UVB induces the subcellular redistribution of AtCOP1 (70) . However, in Arabidopsis thaliana, UVB increased the accumulation of AtCOP1 in the 
nuclei and AtCOP1 has been postulated to regulate UVB responses positively. This is in marked contrast with mammalian cells, in which the immunofluorescence staining of COP1 indicated intensive positivity, mainly in the nucleus, in the absence of UVB $(11,13,15)$. A similar subcellular redistribution of COP1 protein was also detected: ionizing radiation results in the nuclear export of COP1 protein in Flag-COP1-transfected H1299 cells, the primarily nuclear COP1 staining becoming cytosolic after IR (72). In line with the above findings, our results showed that UVB irradiation resulted in a similar decrease in COP1 protein both in the nuclei and in the cytoplasm, and a marked amount of the protein was centered in the perinuclear region of the cytoplasm. This means that in normal keratinocytes UVB irradiation caused not only a significant decrease in the COP1 protein level, but also a notable subcellular redistribution (Fig. 20).

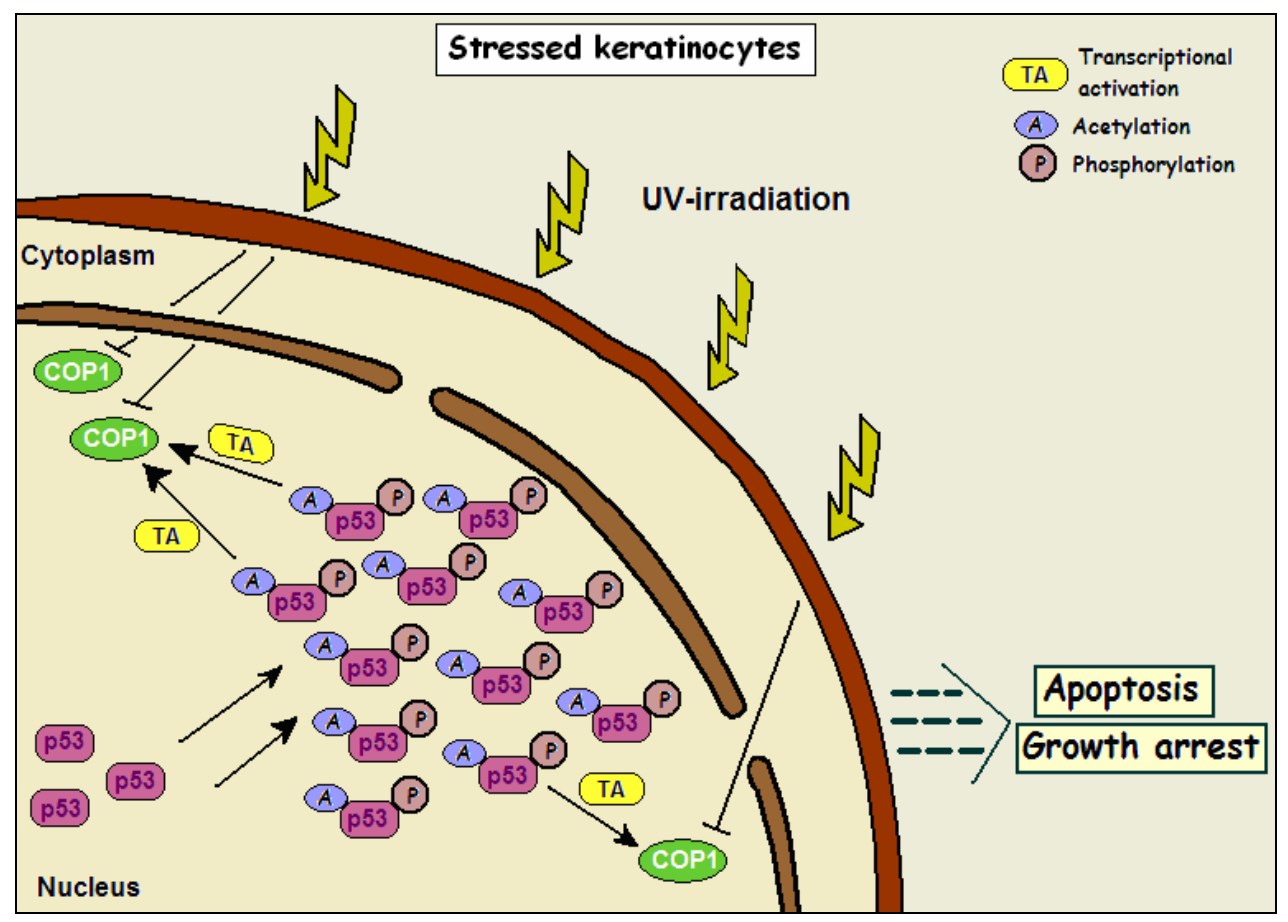

Figure 20. Genotoxic stress, such as UVB irradiation, decreases the level of COP1 protein. The COP1 get into the cytoplasm, and after auto-ubiquitination the protein will be degradated in the proteasome. In depletion of COP1, p53 protein became acetylated and phosphorylated, this results the stabilization of the protein, and apoptosis or growth arrest, depending on the degree of DNA damage. 
The most recent data on COP1 regulation suggest that, besides the above-described expression changes and intracellular movement, ataxia telangiectasia mutated (ATM) protein kinase has a critical role in the regulation of COP1 in the DNA-damage response network: in response to DNA damage, ATM phosphorylates COP1, and stimulates its rapid autodegradation. Genotoxic stress, such as ionizing radiation, promotes the auto-ubiqutination of COP1 and triggers an ATM-dependent movement of the protein from the nucleus to the cytoplasm. Finally, the auto-ubiquitined COP1 may be degraded in the cytoplasmic $26 \mathrm{~S}$ proteasome. This ubiquitination event appears to be entirely dependent on phosphorylation at $\mathrm{Ser}^{387}$, because no ubiquitination of the COP1-S387A mutant was detected: it was refractory to ATM-induced degradation (72).

COP1 is a negative regulator of $\mathrm{p} 53$, and the depletion of COP1 by siRNA therefore stabilizes p53: COP1 silencing resulted in a higher p53 protein level in unstressed U2OS cells (19). In agreement with this, in our experimental set-up we saw that the depletion of COP1 by siRNA in normal keratinocytes resulted in an increase in p53 steady-state levels in unstressed conditions, indicating that COP1 has a negative regulatory role on p53 in keratinocytes too. We investigated the COP1-p53 connection in UVB-induced keratinocytes and found that the UVB irradiation of COP1-silenced keratinocytes resulted in an enhanced accumulation of p53 protein that was evident $24 \mathrm{~h}$ after the irradiation. COP1 silencing and UVB irradiation exerted an additive effect on $\mathrm{p} 53$ protein accumulation. This indicates that depletion of COP1 stabilizes p53 protein in both unstressed cells and UVB-irradiated cells and that the lack of COP1 may sensitize keratinocytes to UVB-induced cell death. Taken together, these results suggest that COP1 has an important role in the UVB response and fine tuning of apoptotic processes of keratinocytes by regulating p53.

We saw that huCOP1 contributes to the UV-induced stress response of keratinocytes. Next, we set out to investigate whether this molecule has any role in the regulation of keratinocyte differentiation and proliferation. We found that COP1 is highly expressed in normal human skin, in both the basal and the granular layers. This suggests that COP1 may have a role in the early steps of differentiation, in which the decision occurs as to whether the basal proliferating cell will enter the proliferation program. HuCOP1 is also expressed in the granular layer of the epidermis, in cells that are in the final stages of differentiation before cell death and cornification. The pleiotropic nature of huCOP1 and its role in complex regulatory 
functions could be revealed when huCOP1 and p53 expressions were studied in different layers of the normal epidermis upon UVB irradiation. p53 levels are low in the normal epidermis, and its induction results in the apoptosis of proliferating keratinocytes; as keratinocytes differentiate, they become insensitive to p53-induced apoptosis $(39,48)$. It is well known that UVB light induces p53 in the proliferative compartment of the basal layer, resulting in protection from the tumorigenic effects of DNA damage (49); in our experiments we detected the opposite: decreases of the huCOP1 level in both the basal and the granular layer.

Consistent with the huCOP1 staining in the epidermis, differentiating keratinocytes express COP1 in the highly proliferative stage. As keratinocytes lose their proliferation potential and begin to express differentiation markers such as involucrin, K1 and K10 $(50,51,53)$, the COP1 expression undergoes a gradual decrease. This decrease was not associated with any changes in the level of p53; in fact, the p53 level did not demonstrate marked changes through differentiation. These in vitro data are in agreement with the immunohistochemical data that huCOP1 is decreased in the suprabasal layer as compared with the basal layer of keratinocytes. The gradual decrease of COP1 protein in differentiating keratinocytes indicates that indeed COP1 is important through p53 regulation in the induction of keratinocytes apoptosis. The reason why fully differentiated, non-proliferative keratinocytes, which do not express p53, still contain COP1 is not clear. Further studies are needed to determine whether COP1 has other functions.

Our in vitro and in vivo data suggest that huCOP1 has a role in the fine tuning of UVB response in keratinocytes via regulation of the p53 function. The high level of huCOP1 in the basal layer of the epidermis, a UV-sensitive proliferating layer, is also an important observation in our experiments, suggesting that huCOP1 has an important role and may function as an oncogene which promotes tumorigenesis in p53-expressing cells, and that interventions targeting huCOP1 could well provide new opportunities in cancer therapy. 


\section{SUMMARY}

COP1 (constitutive photomorphogenic protein 1) was described in the plant Arabidopsis thaliana, as an essential negative regulator of light-mediated plant development. COP1 also exists in non-plant multicellular organisms, although its function is less understood. The huCOP1 shows a high degree of sequence conservation and domain organization with AtCOP1, suggesting the possibility of a functional conservation as well. The huCOP1, like its plant counterpart, is involved in ubiquitination and is itself a substrate of its own ubiquitination activity.

These investigations show that COP1 protein is present in human keratinocytes and immortalized $\mathrm{HaCaT}$ keratinocytes. The huCOP1 is predominantly expressed in the nucleus of keratinocytes under unstressed conditions, and a milder positivity is seen in the cytoplasm. Human epidermis expresses significantly less COP1 mRNA than the colon or gallbladder, but markedly more than in the breast.

UVB light is the most prominent genotoxic stress for keratinocytes, but its effect on COP1 expression has not been investigated previously. In the present study, we found that the COP1 mRNA level showed a biphasic response to UVB. It decreased early after UVB irradiation, and a slow increase was observed after many hours. In contrast with the biphasic mRNA profile the COP1 protein level displayed a steady slow, but marked decrease. UVB irradiation of normal keratinocytes caused not only a significant decrease in the COP1 protein level but also a subcellular redistribution. UVB irradiation resulted in similar decreases inf COP1 protein in both the nuclei and the cytoplasm of keratinocytes and a marked amount of the protein was centered in the perinuclear region of the cytoplasm.

The depletion of COP1 by shRNA in normal keratinocytes resulted in an increase in p53 steady-state levels in unstressed conditions, indicating that COP1 also has a negative regulatory role on p53 in keratinocytes. Irradiation of COP1-silenced keratinocytes with UVB light resulted in an accumulation of p53 protein that was evident $24 \mathrm{~h}$ after the irradiation. COP1 silencing and UVB irradiation had an additive effect on $\mathrm{p} 53$ protein accumulation. This indicates that the depletion of COP1 stabilizes p53 protein both in unstressed cells and UVBirradiated cells and that the lack of COP1 may sensitize keratinocytes to UVB-induced cell death. 
We found that COP1 is highly expressed in normal human skin, in both the basal and the granular layers. This suggests that COP1 may have a role in the early steps of differentiation and is also expressed in the granular layer of the epidermis, in cells that are in the final stages of differentiation before cell death and cornification. The pleiotropic nature of huCOP1 and its role in complex regulatory functions were revealed when huCOP1 and p53 expressions were studied in different layers of the normal epidermis in response to UVB irradiation. While UVB light induces p53 in the proliferative compartment of the basal layer, resulting in protection from the tumorigenic effects of DNA damage, we detected decreases in huCOP1 level in both the basal and the granular layer.

Consistent with the huCOP1 staining in the epidermis, differentiating keratinocytes express COP1 in the highly proliferative stage. As keratinocytes lose their proliferation potential, COP1 expression exhibits a gradual decrease. This decrease is not associated with any changes in the level of p53; in fact, the p53 level did not show marked changes through differentiation.

Our in vitro and in vivo data suggest that huCOP1 has a role in the fine tuning of the UVB response in keratinocytes via regulation of the p53 function. The high level of huCOP1 in the basal layer of the epidermis, a UV-sensitive proliferating layer, is also an important observation in our experiments, suggesting that huCOP1 has an important role and may function as an oncogene which promotes tumorigenesis in p53-expressing cells, and interventions targeting huCOP1 could well provide new opportunities in cancer therapy. 


\section{ACKNOWLEDGMENTS}

I would like to thank to Prof. Dr. Lajos Kemény for the possibility to perform these studies in the laboratory of the Department of Dermatology and Allergology, University of Szeged, and for his supervision of this work. Special thanks are due to Prof. Dr. Ferenc Nagy for his excellent suggestions and invaluable advice.

I thank Prof. Dr. Márta Széll for her constant support and advice, Dr. Zsuzsanna KissLászló and Dr. Mária Kiss for their support, and Prof. Dr. Zsuzsanna Bata-Csörgő for her valuable discussions.

I am grateful to my collagues Szabolcs Hambalkó and Attila Bebes. I further thank Bernadett Kormos, Andrea Tanácsné Bajkán and Hilda Polyánka for their help in the preparative work. Special thanks are also due to Dr. Nikoletta Nagy for her constant support.

I am likewise very grateful to all collagues who have provided me with so much help in my work.

This work was supported by the TÁMOP-4.2.2-08/1. and TÁMOP 4.2.1.B grants, and by the Loreal Inc (Hungary). The Project named „TÁMOP-4.2.1/B-09/1/KONV-20100005 - Creating the Center of Excellence at the University of Szeged" is supported by the European Union and co-financed by the European Regional Fund.

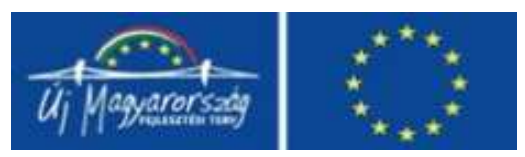

www.nfu.hu 


\section{REFERENCES}

1. Ulm R, Baumann A, Oravecz A et al. Genome-wide analysis of gene expression reveals function of the bZIP transcription factor HY5 in the UV-B response of Arabidopsis. Proc Natl Acad Sci U S A 2004: 101: 1397-1402.

2. Sesto A, Navarro M, Burslem F, Jorcano JL. Analysis of the ultraviolet B response in primary human keratinocytes using oligonucleotide microarrays. Proc Natl Acad Sci U S A 2002: 99: 2965-2970.

3. Yang G, Zhang G, Pittelkow MR, Ramoni M, Tsao H. Expression profiling of UVB response in melanocytes identifies a set of p53-target genes. J Invest Dermatol 2006: 126: 2490-2506.

4. Howell BG, Wang B, Freed I, Mamelak AJ, Watanabe H, Sauder DN. Microarray analysis of UVB-regulated genes in keratinocytes: downregulation of angiogenesis inhibitor thrombospondin-1. J Dermatol Sci 2004: 34: 185194.

5. Latonen L, Laiho M. Cellular UV damage responses--functions of tumor suppressor p53. Biochim Biophys Acta 2005: 1755: 71-89.

6. Bauer D, Viczian A, Kircher S et al. Constitutive photomorphogenesis 1 and multiple photoreceptors control degradation of phytochrome interacting factor 3 , a transcription factor required for light signaling in Arabidopsis. Plant Cell 2004: 16: 1433-1445.

7. Deng XW, Caspar T, Quail PH. cop1: a regulatory locus involved in lightcontrolled development and gene expression in Arabidopsis. Genes Dev 1991: 5: $1172-1182$.

8. Torii KU, McNellis TW, Deng XW. Functional dissection of Arabidopsis COP1 reveals specific roles of its three structural modules in light control of seedling development. EMBO J 1998: 17: 5577-5587.

9. Osterlund MT, Hardtke CS, Wei N, Deng XW. Targeted destabilization of HY5 during light-regulated development of Arabidopsis. Nature 2000: 405: 462-466.

10. Holm M, Deng XW. Structural organization and interactions of COP1, a lightregulated developmental switch. Plant Mol Biol 1999: 41: 151-158.

11. Yi C, Deng XW. COP1 - from plant photomorphogenesis to mammalian tumorigenesis. Trends Cell Biol 2005: 15: 618-625. 
12. von Arnim AG, Deng XW. Light inactivation of Arabidopsis photomorphogenic repressor COP1 involves a cell-specific regulation of its nucleocytoplasmic partitioning. Cell 1994: 79: 1035-1045.

13. Bianchi E, Denti S, Catena R et al. Characterization of human constitutive photomorphogenesis protein 1, a RING finger ubiquitin ligase that interacts with Jun transcription factors and modulates their transcriptional activity. $\mathbf{J}$ Biol Chem 2003: 278: 19682-19690.

14. Stacey MG, Kopp OR, Kim TH, von Arnim AG. Modular domain structure of Arabidopsis COP1. Reconstitution of activity by fragment complementation and mutational analysis of a nuclear localization signal in planta. Plant Physiol 2000: 124: 979-990.

15. Yi C, Wang H, Wei N, Deng XW. An initial biochemical and cell biological characterization of the mammalian homologue of a central plant developmental switch, COP1. BMC Cell Biol 2002: 3: 30.

16. von Arnim AG, Deng XW. Ring finger motif of Arabidopsis thaliana COP1 defines a new class of zinc-binding domain. J Biol Chem 1993: 268: 1962619631.

17. Wertz IE, O'Rourke KM, Zhang Z et al. Human De-etiolated-1 regulates c-Jun by assembling a CUL4A ubiquitin ligase. Science 2004: 303: 1371-1374.

18. Reyes JC. PML and COP1--two proteins with much in common. Trends Biochem Sci 2001: 26: 18-20.

19. Dornan D, Wertz I, Shimizu H et al. The ubiquitin ligase COP1 is a critical negative regulator of p53. Nature 2004: 429: 86-92.

20. Yi C, Li S, Chen X et al. Major vault protein, in concert with constitutively photomorphogenic 1 , negatively regulates c-Jun-mediated activator protein 1 transcription in mammalian cells. Cancer Res 2005: 65: 5835-5840.

21. Crawford LV, Pim DC, Gurney EG, Goodfellow P, Taylor-Papadimitriou J. Detection of a common feature in several human tumor cell lines--a 53,000dalton protein. Proc Natl Acad Sci U S A 1981: 78: 41-45.

22. Campbell C, Quinn AG, Angus B, Farr PM, Rees JL. Wavelength specific patterns of p53 induction in human skin following exposure to UV radiation. Cancer Res 1993: 53: 2697-2699.

23. Henseleit U, Zhang J, Wanner R, Haase I, Kolde G, Rosenbach T. Role of p53 in UVB-induced apoptosis in human $\mathrm{HaCaT}$ keratinocytes. J Invest Dermatol 1997: 109: 722-727. 
24. Hollstein M, Sidransky D, Vogelstein B, Harris CC. p53 mutations in human cancers. Science 1991: 253: 49-53.

25. Minamoto $\mathrm{T}$, Buschmann $\mathrm{T}$, Habelhah $\mathrm{H}$ et al. Distinct pattern of $\mathrm{p} 53$ phosphorylation in human tumors. Oncogene 2001: 20: 3341-3347.

26. Einspahr JG, Alberts DS, Warneke JA et al. Relationship of p53 mutations to epidermal cell proliferation and apoptosis in human UV-induced skin carcinogenesis. Neoplasia 1999: 1: 468-475.

27. Weinberg WC, Azzoli CG, Chapman K, Levine AJ, Yuspa SH. p53-mediated transcriptional activity increases in differentiating epidermal keratinocytes in association with decreased p53 protein. Oncogene 1995: 10: 2271-2279.

28. Kasiappan R, Shih HJ, Wu MH et al. The antagonism between MCT-1 and p53 affects the tumorigenic outcomes. Mol Cancer 2010: 9: 311.

29. Einspahr J, Alberts DS, Aickin M et al. Expression of p53 protein in actinic keratosis, adjacent, normal-appearing, and non-sun-exposed human skin. Cancer Epidemiol Biomarkers Prev 1997: 6: 583-587.

30. Ling G, Persson A, Berne B, Uhlen M, Lundeberg J, Ponten F. Persistent p53 mutations in single cells from normal human skin. Am J Pathol 2001: 159: 1247-1253.

31. Leng RP, Lin $\mathrm{Y}, \mathrm{Ma} \mathrm{W}$ et al. Pirh2, a p53-induced ubiquitin-protein ligase, promotes p53 degradation. Cell 2003: 112: 779-791.

32. Li DQ, Divijendra Natha RS, Pakala SB et al. MTA1 coregulator regulates p53 stability and function. J Biol Chem 2009: 284: 34545-34552.

33. Moll UM, Petrenko O. The MDM2-p53 interaction. Mol Cancer Res 2003: 1: 1001-1008.

34. Berg RJ, van Kranen HJ, Rebel HG et al. Early p53 alterations in mouse skin carcinogenesis by UVB radiation: immunohistochemical detection of mutant p53 protein in clusters of preneoplastic epidermal cells. Proc Natl Acad Sci U S A 1996: 93: 274-278.

35. Maltzman W, Czyzyk L. UV irradiation stimulates levels of p53 cellular tumor antigen in nontransformed mouse cells. Mol Cell Biol 1984: 4: 1689-1694.

36. Verschooten L, Declercq L, Garmyn M. Adaptive response of the skin to UVB damage: role of the p53 protein. Int J Cosmet Sci 2006: 28: 1-7.

37. Davenport V, Morris JF, Motazed R, Chu AC. p53 induction in normal human skin in vitro following exposure to solar simulated UV and UV-B irradiation. $\mathrm{J}$ Photochem Photobiol B 1999: 49: 177-186. 
38. Chaturvedi V, Qin JZ, Stennett L, Choubey D, Nickoloff BJ. Resistance to $\mathrm{UV}$-induced apoptosis in human keratinocytes during accelerated senescence is associated with functional inactivation of p53. J Cell Physiol 2004: 198: 100109.

39. Ganguli G, Wasylyk B. p53-independent functions of MDM2. Mol Cancer Res 2003: 1: 1027-1035.

40. Dazard JE, Piette J, Basset-Seguin N, Blanchard JM, Gandarillas A. Switch from p53 to MDM2 as differentiating human keratinocytes lose their proliferative potential and increase in cellular size. Oncogene 2000: 19: 36933705 .

41. Alkhalaf M, Ganguli G, Messaddeq N, Le Meur M, Wasylyk B. MDM2 overexpression generates a skin phenotype in both wild type and p53 null mice. Oncogene 1999: 18: 1419-1434.

42. Jiang W, Ananthaswamy HN, Muller HK, Kripke ML. p53 protects against skin cancer induction by UV-B radiation. Oncogene 1999: 18: 4247-4253.

43. Corcoran CA, Huang Y, Sheikh MS. The p53 paddy wagon: COP1, Pirh2 and MDM2 are found resisting apoptosis and growth arrest. Cancer Biol Ther 2004: 3: 721-725.

44. Yu ZK, Geyer RK, Maki CG. MDM2-dependent ubiquitination of nuclear and cytoplasmic P53. Oncogene 2000: 19: 5892-5897.

45. Li M, Brooks CL, Wu-Baer F, Chen D, Baer R, Gu W. Mono- versus polyubiquitination: differential control of p53 fate by Mdm2. Science 2003: 302: 1972-1975.

46. Brooks CL, Gu W. p53 ubiquitination: Mdm2 and beyond. Mol Cell 2006: 21: 307-315.

47. Wang L, He G, Zhang P, Wang X, Jiang M, Yu L. Interplay between MDM2, MDMX, Pirh2 and COP1: the negative regulators of p53. Mol Biol Rep 2011: 38: $229-236$.

48. Ganguli G, Abecassis J, Wasylyk B. MDM2 induces hyperplasia and premalignant lesions when expressed in the basal layer of the epidermis. EMBO J 2000: 19: 5135-5147.

49. Qin JZ, Chaturvedi V, Denning MF et al. Regulation of apoptosis by p53 in UV-irradiated human epidermis, psoriatic plaques and senescent keratinocytes. Oncogene 2002: 21: 2991-3002.

50. Brysk MM, Arany I, Brysk H, Chen SH, Calhoun KH, Tyring SK. Gene expression of markers associated with proliferation and differentiation in 
human keratinocytes cultured from epidermis and from buccal mucosa. Arch Oral Biol 1995: 40: 855-862.

51. Fuchs E. Epidermal differentiation: the bare essentials. J Cell Biol 1990: 111: 2807-2814.

52. Sherman L, Jackman A, Itzhaki H, Stoppler MC, Koval D, Schlegel R. Inhibition of serum- and calcium-induced differentiation of human keratinocytes by HPV16 E6 oncoprotein: role of p53 inactivation. Virology 1997: 237: 296-306.

53. Banks-Schlegel S, Green H. Involucrin synthesis and tissue assembly by keratinocytes in natural and cultured human epithelia. J Cell Biol 1981: 90: 732-737.

54. Yoneda-Kato N, Tomoda K, Umehara M, Arata Y, Kato JY. Myeloid leukemia factor 1 regulates p53 by suppressing COP1 via COP9 signalosome subunit 3. EMBO J 2005: 24: 1739-1749.

55. Perry ME. Mdm2 in the response to radiation. Mol Cancer Res 2004: 2: 9-19.

56. Perry ME, Piette J, Zawadzki JA, Harvey D, Levine AJ. The mdm-2 gene is induced in response to UV light in a p53-dependent manner. Proc Natl Acad Sci U S A 1993: 90: 11623-11627.

57. Brash DE, Wikonkal NM, Remenyik E et al. The DNA damage signal for Mdm2 regulation, Trp53 induction, and sunburn cell formation in vivo originates from actively transcribed genes. J Invest Dermatol 2001: 117: 12341240 .

58. Savio MG, Rotondo G, Maglie S, Rossetti G, Bender JR, Pardi R. COP1D, an alternatively spliced constitutive photomorphogenic-1 (COP1) product, stabilizes UV stress-induced c-Jun through inhibition of full-length COP1. Oncogene 2008: 27: 2401-2411.

59. Dornan D, Bheddah $\mathrm{S}$, Newton $\mathrm{K}$ et al. COP1, the negative regulator of $\mathrm{p} 53$, is overexpressed in breast and ovarian adenocarcinomas. Cancer Res 2004: 64: 7226-7230.

60. Lee YH, Andersen JB, Song HT et al. Definition of ubiquitination modulator COP1 as a novel therapeutic target in human hepatocellular carcinoma. Cancer Res 2010: 70: 8264-8269.

61. Brummelkamp TR, Bernards R, Agami R. A system for stable expression of short interfering RNAs in mammalian cells. Science 2002: 296: 550-553. 
62. Distler JH, Jungel A, Kurowska-Stolarska $M$ et al. Nucleofection: a new, highly efficient transfection method for primary human keratinocytes*. Exp Dermatol 2005: 14: 315-320.

63. Novak Z, Berces A, Ronto G, Pallinger E, Dobozy A, Kemeny L. Efficacy of different UV-emitting light sources in the induction of T-cell apoptosis. Photochem Photobiol 2004: 79: 434-439.

64. Grof P, Ronto G, Sage E. A computational study of physical and biological characterization of common UV sources and filters, and their relevance for substituting sunlight. J Photochem Photobiol B 2002: 68: 53-59.

65. Belso N, Szell M, Pivarcsi A et al. Differential expression of D-type cyclins in $\mathrm{HaCaT}$ keratinocytes and in psoriasis. J Invest Dermatol 2008: 128: 634-642.

66. Nagy N, Nemeth IB, Szabad G et al. The altered expression of syndecan 4 in the uninvolved skin of venous leg ulcer patients may predispose to venous leg ulcer. Wound Repair Regen 2008: 16: 495-502.

67. Sonkoly E, Bata-Csorgo Z, Pivarcsi A et al. Identification and characterization of a novel, psoriasis susceptibility-related noncoding RNA gene, PRINS. J Biol Chem 2005: 280: 24159-24167.

68. Mazzucotelli E, Belloni S, Marone D et al. The e 3 ubiquitin ligase gene family in plants: regulation by degradation. Curr Genomics 2006: 7: 509-522.

69. Suzuki G, Yanagawa Y, Kwok SF, Matsui M, Deng XW. Arabidopsis COP10 is a ubiquitin-conjugating enzyme variant that acts together with COP1 and the COP9 signalosome in repressing photomorphogenesis. Genes Dev 2002: 16: 554-559.

70. Oravecz A, Baumann A, Mate $\mathrm{Z}$ et al. CONSTITUTIVELY PHOTOMORPHOGENIC1 is required for the UV-B response in Arabidopsis. Plant Cell 2006: 18: 1975-1990.

71. Lehman TA, Modali R, Boukamp $\mathrm{P}$ et al. p53 mutations in human immortalized epithelial cell lines. Carcinogenesis 1993: 14: 833-839.

72. Dornan D, Shimizu H, Mah A et al. ATM engages autodegradation of the E3 ubiquitin ligase COP1 after DNA damage. Science 2006: 313: 1122-1126.

73. Su CH, Zhao R, Velazquez-Torres $\mathrm{G}$ et al. Nuclear export regulation of COP1 by 14-3-3sigma in response to DNA damage. Mol Cancer 2010: 9: 243. 